Check for updates

Cite this: RSC Adv., 2019, 9, 36455

Received 4th September 2019

Accepted 28th October 2019

DOI: 10.1039/c9ra07105a

rsc.li/rsc-advances

\section{Experimental and theoretical insights into the corrosion inhibition activity of novel Schiff bases for aluminum alloy in acidic medium $\uparrow$}

\begin{abstract}
Uzma Nazir, (D) ${ }^{a}$ Zareen Akhter, ${ }^{* a}$ Naveed Zafar Alib and Faiz Ullah Shah (D) *c
Three novel Schiff bases, namely $N$-(4-((4-((phenylimino)methyl)phenoxy)methoxy)benzylidene)benzenamine (UA), N-(3-methoxy-4-((2-methoxy-4-((phenylimino)methyl)phenoxy)methoxy)benzylidene)benzenamine (UB), and $\mathrm{N}$-(3-ethyl-4-((2-ethyl-4-((phenylimino)methyl)phenoxy)methoxy)benzylidene)benzenamine (UC), were synthesized and their structures were elucidated through diverse spectroscopic techniques such as FT-IR, GCMS, ${ }^{1} \mathrm{H}$ NMR and ${ }^{13} \mathrm{C}$ NMR. The corrosion inhibition effect of these Schiff bases on aluminum alloy AA2219-T6 in acidic medium was explored using weight loss, Tafel polarization, and electrochemical impedance spectroscopy. Theoretical quantum chemical calculations using density functional theory were employed to determine the adsorption site. It was found that inhibition efficiencies increase with an increase in the inhibitor concentration. Tafel plots showed that these Schiff bases function as mixed inhibitors. Adsorption of the Schiff bases on aluminum followed the Langmuir adsorption isotherm and the value of $\Delta G_{\text {ads }}^{\circ}$ showed a dominant chemical mechanism. FT-IR and SEM techniques were used to investigate the surface morphology. The compounds showed a substantial corrosion inhibition for aluminum alloy in $0.1 \mathrm{M} \mathrm{HCl}$ at $298 \mathrm{~K}$. UB and UC exhibited superior anticorrosion efficiency compared to UA originating from the electron-donating methoxy and ethoxy group substitutions, respectively. There was found to be good correlation between molecular structure and inhibition efficiencies.
\end{abstract}

\section{Introduction}

Aluminum and its alloys containing excess copper contents (i.e. the AA2000 series) are some of the most widely used materials owing to their low density, oxidation resistance and prevailing mechanical strength. They are widely used in the marine, electronic $^{1}$ and aerospace industries ${ }^{2}$ with diverse structural applications. The increasing ocean acidification due to the excessive release of carbon dioxide to the atmosphere and its dissolution in sea water poses a threat not only to aquaculture, flora, biodiversity, and fisheries but is also becoming alarming in terms of the biofouling of offshore and deep-sea structures and sea-related economies. The resulting rusting and scaling of eroded metal surfaces are often cleaned using dilute hydrochloric acid that removes emergent abrasive signatures in submerged hull and marine wreckages. The need to develop effective protection measures in the form of smart anticorrosive coatings and effective corrosion inhibitors is imperative, which

\footnotetext{
${ }^{a}$ Department of Chemistry, Quaid-i-Azam University, Islamabad 45320, Pakistan. E-mail: zareenakhter@yahoo.com

${ }^{b}$ National Center for Physics, Quaid-i-Azam University Campus, Islamabad, Pakistan 'Chemistry of Interfaces, Luleå University of Technology, 97187 Luleå, Sweden. E-mail: faiz.ullah@ltu.se
}

$\dagger$ Electronic supplementary information (ESI) available. See DOI: 10.1039/c9ra07105a will help to tackle the chronic corrosion problem and allied economic losses.

The high reactivity of aluminum and its alloys renders them vulnerable to corrosion in aggressive environments. ${ }^{3}$ Despite the fact that an adhesive and protective passivating oxide film is formed due to exposure to aqueous solution on the surface of aluminum, this film has an amphoteric receptivity and easily dissolves when metal is prone to high acidic or basic concentrations. ${ }^{4,5}$ Corrosion is a phenomenon that brings about the destruction of metal structures via chemical and/or electrochemical reactions. ${ }^{6}$ Metal degradation through corrosion is a major problem in industrial applications, hence directly leading to economic losses. For pickling, chemical or electrochemical etching of aluminum, hydrochloric acid solutions are used, which corrode this metal. Therefore inhibition of corrosion of aluminum in acidic media has pronounced importance. ${ }^{7,8}$ The main strategy to overcome the corrosion of aluminum is to protect it from corrosive compounds. For this purpose organic corrosion inhibitors that contain polar groups, heteroatoms such as nitrogen, oxygen and sulfur in their structure and an electronic cloud on aromatic rings are reported.9-11

Presently, among various categories of organic anticorrosive compounds, Schiff bases are the prime class used to prevent corrosion. The main reasons for using Schiff bases as potential anticorrosive materials are that they are easily synthesized from comparatively inexpensive starting materials and are eco- 
friendly. ${ }^{12,13}$ These anticorrosive molecules normally form very fine and permanent adsorbed films that are helpful in reducing the disintegration rate of a metal by preventing anodic and cathodic reactions. ${ }^{14}$ Various studies have shown that the main mechanism through which a metal surface is protected by anticorrosive molecules is the formation of donor-acceptor complexes. Thus, inhibition efficiency mainly depends upon structural frameworks including functional groups, donor atom electron density and electronic structure of the adsorbed molecules and substrates. ${ }^{15-18}$ Various Schiff bases have been reported to prevent degradation of metals and alloys such as pure aluminum and its alloys, ${ }^{19-23}$ copper, ${ }^{24}$ iron and mild steel $^{25-27}$ in acidic environments.

Theoretical approaches have gained ample consideration in fundamental corrosion studies. ${ }^{28,29}$ In this regard, quantum chemical calculations have been extensively used to analyze the molecular structures of anticorrosive compounds and their interrelation with metal substrates at a molecular level, which is crucial for perceiving the inhibition effectiveness of adsorbates. ${ }^{30-34}$ Organic inhibitors of different anticorrosive efficiencies are evidenced by measuring the optimum configuration of the organic molecules that are adsorbed on to a metal surface and by evaluating their interaction energies. ${ }^{34}$

According to the existing literature, not many studies have been carried out regarding the corrosion inhibition of aluminum alloys of the 2000 series in acidic media by organic Schiff bases. And to the best of our knowledge, no anticorrosive research work has been reported so far on aluminum-copper alloy AA2219-T6. Therefore, the inhibitive behavior of some organic Schiff bases with different substituents and heteroatoms on AA2219-T6 alloy towards corrosion in acidic media was thoroughly studied using both experimental and theoretical approaches.

The present work is aimed at the synthesis of three organic Schiff bases, namely $N$-(4-((4-((phenylimino)methyl)phenoxy) methoxy)benzylidene)benzenamine (UA), $N$-(3-methoxy-4-((2methoxy-4-((phenylimino)methyl)phenoxy)methoxy)

benzylidene)benzenamine (UB), and $N$-(3-ethyl-4-((2-ethyl-4((phenylimino)methyl)phenoxy)methoxy)benzylidene)

benzenamine (UC), to investigate corrosion inhibition of AA2219-T6 alloy in $0.1 \mathrm{M} \mathrm{HCl}$ medium. The main focus of this study was to investigate the effect of substitution of ethoxy $\left(-\mathrm{OC}_{2} \mathrm{H}_{5}\right)$ and methoxy $\left(-\mathrm{OCH}_{3}\right)$ groups on their anticorrosive properties. The substitution effect of ethoxy $\left(-\mathrm{OC}_{2} \mathrm{H}_{5}\right)$ and methoxy $\left(-\mathrm{OCH}_{3}\right)$ groups on the inhibitive properties of the Schiff bases is studied using weight loss measurement technique, potentiodynamic polarization and electrochemical impedance spectroscopy (EIS). Moreover, quantum chemical calculations have been performed using density functional theory (DFT) to investigate the anticorrosion mechanism and its correlation with electronic and structural properties of the organic inhibitors. The correlations between inhibition effectiveness and theoretical parameters such as energies of the highest occupied molecular orbital $\left(E_{\text {Hомо }}\right)$ and the lowest unoccupied molecular orbital ( $\left.E_{\text {LUMO }}\right)$, energy difference $(\Delta E)$, electronegativity $(\chi)$, dipole moment $(\mu)$, etc., are discussed. Aluminum alloy surface morphology after corrosion experiments was inspected by FT-IR spectroscopy and scanning electron microscopic (SEM) techniques.

\section{Experimental}

\subsection{Materials and methods}

All chemicals used in the present study were of analytical grade and subsequently used for experiments as received from commercial suppliers without further purification. 4-Hydroxybenzaldehyde, 4-hydroxy-3-methoxybenzaldehyde, and 3ethoxy-4-hydroxybenzaldehyde were obtained from Fluka in pure form. Hydrochloric acid, aniline, dichloromethane and anhydrous potassium carbonate were purchased in pure form from Merck. Absolute ethanol and dimethyl formamide (DMF) were further purified before use, following standard analytical methods. ${ }^{35}$

The structure and purity of the synthesized Schiff bases were characterized using a Bruker Ascend Aeon WB 400 (Bruker BioSpin AG, Fällanden, Switzerland) NMR spectrometer. Some spectra were recorded with Bruker AXR (300 MHz) spectrometer. Data were processed using Bruker Topspin 3.5 software. Vibration frequencies of all the Schiff bases were recorded through FTIR spectra, using a PerkinElmer System 2000, in which sampling accessory was built in with ATR. GC-MS of the inhibitor Schiff bases was done through mass selective detector G2579A.

\subsection{Preparation of Schiff bases}

The investigated Schiff bases were synthesized in two steps. In the first step, substituted diformyl precursors were prepared by condensing 4-hydroxybenzaldehyde with appropriate $\alpha, \omega$ dichloroalkanes in an inert atmosphere, in the presence of anhydrous potassium carbonate using DMF as solvent. Then in the second step, the Schiff bases were synthesized through condensation of $2.1 \mathrm{~mol}$ of dried aniline with $1 \mathrm{~mol}$ of corresponding diformyl compound by adopting the following route. In a round-bottom flask of $250 \mathrm{~mL}$ equipped with a magnetic stirrer and a condenser, one mole of dialdehyde was dissolved in $50 \mathrm{~mL}$ of dried absolute ethanol. Concurrently the mixture/solution of dried aniline $(2.1 \mathrm{~mol})$ in absolute ethanol $(30 \mathrm{~mL})$ was added dropwise to this solution within 30 minutes under streaming $\mathrm{N}_{2}$. The mixture was then heated at $90{ }^{\circ} \mathrm{C}$ to reflux for $6-7 \mathrm{~h}$ leading to the formation of reaction product as observed by TLC [ $n$ hexane/ethyl acetate $(6: 4)]$. At the end of reaction, the reaction mixture was cooled and white-colored Schiff base precipitated out which was subsequently filtered and recrystallized from dried ethanol to afford the corresponding pristine Schiff base.

\subsubsection{N-(4-((4-((Phenylimino)methyl)phenoxy)methoxy)} benzylidene)benzenamine (UA). The Schiff base UA was synthesized by the above-mentioned procedure using dialdehyde (2 g, $7.80 \mathrm{mmol}$ ) 4,4'-diformyldiphenoxyethane with aniline (1.528 mL, $7.81 \mathrm{mmol}$ ). Yield 70\%; m.p. 136-139 ${ }^{\circ} \mathrm{C}$; GC-MS: $\mathrm{C}_{27} \mathrm{H}_{22} \mathrm{~N}_{2} \mathrm{O}_{2}(\mathrm{~m} / \mathrm{z})$ : obs. $406 \mathrm{amu}\left[\mathrm{M}^{+}\right]$, calcd $(\mathrm{m} / \mathrm{z})=406 \mathrm{amu}$ $\left[\mathrm{M}^{+}\right], m / z=226\left[\mathrm{M}-\mathrm{C}_{13} \mathrm{H}_{10} \mathrm{~N}\right]^{+}, m / z=104\left[\mathrm{M}-\mathrm{C}_{20} \mathrm{H}_{16} \mathrm{~N}_{2} \mathrm{O}_{2}\right]^{+}, m /$ $z=77\left[\mathrm{M}-\mathrm{C}_{21} \mathrm{H}_{17} \mathrm{~N}_{2} \mathrm{O}_{2}\right]^{+}$. FT-IR $\left(\nu \mathrm{cm}^{-1}\right): \nu(\mathrm{C}=\mathrm{N}) 1605 \mathrm{~s} ; \nu(\mathrm{C}-\mathrm{O}-$ C) $1219 ; \nu(\mathrm{Ar}-\mathrm{CH}) 3061 \mathrm{~s} ; \nu$ (aliphatic-CH) 2879. ${ }^{1} \mathrm{H}$ NMR $\left(\mathrm{CDCl}_{3}\right.$; $\delta$ ppm): $8.42(1 \mathrm{H}, \mathrm{HC}=\mathrm{N}) ; 6.46\left(2 \mathrm{H}, \mathrm{O}-\mathrm{CH}_{2}-\mathrm{O}\right) ; 7.21-7.91(9 \mathrm{H}, J$ 
$=8.4, \mathrm{Ar}-\mathrm{H}) .{ }^{13} \mathrm{C} \mathrm{NMR}\left(\mathrm{CDCl}_{3} ; \delta \mathrm{ppm}\right): 159.0(1 \mathrm{C}, \mathrm{HC}=\mathrm{N}) ; 101.02$ (s, aliphatic $\left.\mathrm{C},-\mathrm{CH}_{2}-\right)$; 116.48-152.19 (m, aromatic C).

2.2.2 N-(3-Methoxy-4-((2-methoxy-4-((phenylimino)methyl) phenoxy)methoxy)benzylidene)benzenamine (UB). The Schiff base UB was synthesized by the aforementioned procedure using 4,4'-diformyl-bis-methoxydiphenoxyethane (2 g, 6.32 mmol) with aniline (1.21 mL, $6.19 \mathrm{mmol})$. Yield 77\%; m.p. 98$101{ }^{\circ} \mathrm{C}$; GC-MS: $\mathrm{C}_{27} \mathrm{H}_{22} \mathrm{~N}_{2} \mathrm{O}_{2} \mathrm{~m} / z=466[\mathrm{M}]^{+}, \mathrm{m} / \mathrm{z}=226[\mathrm{M}-$ $\left.\mathrm{C}_{15} \mathrm{H}_{12} \mathrm{NO}_{2}\right]^{+}, m / z=240\left[\mathrm{M}-\mathrm{C}_{14} \mathrm{H}_{14} \mathrm{NO}_{2}\right]^{+}, m / z=77[\mathrm{M}-$ $\left.\mathrm{C}_{23} \mathrm{H}_{20} \mathrm{~N}_{2} \mathrm{O}_{4}\right]^{+}, m / z=388\left[\mathrm{M}-\mathrm{C}_{6} \mathrm{H}_{5}\right]^{+}$. FT-IR $\left(\nu \mathrm{cm}^{-1}\right): \nu(\mathrm{C}=\mathrm{N})$ $1585 \mathrm{~s} ; \nu(\mathrm{C}-\mathrm{O}-\mathrm{C}) 1249 ; \nu(\mathrm{Ar}-\mathrm{CH}) 3054 \mathrm{~s} ; \nu$ (aliphatic-CH) 2972. ${ }^{1} \mathrm{H} \mathrm{NMR}\left(\mathrm{CDCl}_{3} ; \delta \mathrm{ppm}\right): 8.41(1 \mathrm{H}, \mathrm{HC}=\mathrm{N}) ; 6.59\left(2 \mathrm{H}, \mathrm{O}-\mathrm{CH}_{2}-\mathrm{O}\right)$; $3.98\left(3 \mathrm{H}, \mathrm{s}, \mathrm{OCH}_{3}\right) ; 7.20-7.67(8 \mathrm{H}, \mathrm{m}, J=8.4, \mathrm{Ar}-\mathrm{H}) .{ }^{13} \mathrm{C} \mathrm{NMR}$ $\left(\mathrm{CDCl}_{3} ; \delta \mathrm{ppm}\right): 159.69(1 \mathrm{C}, \mathrm{HC}=\mathrm{N}) ; 101.03$ (s, aliphatic $\mathrm{C}$, $\left.-\mathrm{CH}_{2}-\right)$; 56.5 (1C, $\left.\mathrm{OCH}_{3}\right) ; 116.48-152.19$ (m, aromatic C).

2.2.3 N-(3-Ethyl-4-((2-ethyl-4-((phenylimino)methyl) phenoxy)methoxy)benzylidene)benzenamine (UC). The Schiff base UC was synthesized following the above general procedure using $2.0 \mathrm{~g}$ ( $5.81 \mathrm{mmol})$ of 4,4'-diformyl-bis-ethoxydiphenoxyethane with aniline (1.21 mL, $6.19 \mathrm{mmol})$. Yield 67\%; m.p. $220{ }^{\circ} \mathrm{C}$; GC-MS: $\mathrm{C}_{27} \mathrm{H}_{22} \mathrm{~N}_{2} \mathrm{O}_{2} m / z=494[\mathrm{M}]^{+}, m / z=254\left[\mathrm{M}-\mathrm{C}_{25} \mathrm{H}_{14} \mathrm{NO}_{2}\right]^{+}, m / z=$ $226\left[\mathrm{M}-\mathrm{C}_{16} \mathrm{H}_{16} \mathrm{NO}_{2}\right]^{+}, m / z=77\left[\mathrm{M}-\mathrm{C}_{25} \mathrm{H}_{25} \mathrm{~N}_{2} \mathrm{O}_{4}\right]^{+}, m / z=417[\mathrm{M}$ $\left.-\mathrm{C}_{6} \mathrm{H}_{5}\right]^{+}$. FT-IR $\left(\nu \mathrm{cm}^{-1}\right): \nu(\mathrm{C}=\mathrm{N}) 1600 \mathrm{~s} ; \nu(\mathrm{C}-\mathrm{O}-\mathrm{C}) 1245 ; \nu(\mathrm{Ar}-\mathrm{CH})$ $3062 \mathrm{~s} ; \nu$ (aliphatic-CH) 2875. ${ }^{1} \mathrm{H}$ NMR (acetone; $\left.\delta \mathrm{ppm}\right): 8.51(1 \mathrm{H}$, $\mathrm{HC}=\mathrm{N}) ; 4.13\left(2 \mathrm{H}, \mathrm{q}, J=6.9, \mathrm{ArOCH}_{2}\right) ; 1.40\left(3 \mathrm{H}, \mathrm{t}, J=6.9, \mathrm{CH}_{3}\right)$; $5.96\left(2 \mathrm{H}, \mathrm{s},-\mathrm{CH}_{2}-\right) ; 7.21-7.70(8 \mathrm{H}, \mathrm{m}, J=8.4, \mathrm{Ar}-\mathrm{H}) .{ }^{13} \mathrm{C} \mathrm{NMR}$ (acetone; $\delta \mathrm{ppm}): 159.54(\mathrm{HC}=\mathrm{N}) ; 101.20\left(1 \mathrm{C}, \mathrm{O}-\mathrm{CH}_{2}-\mathrm{O}\right) ; 64.19$ $\left(1 \mathrm{C}, \mathrm{OCH}_{2}\right) ; 14.50\left(1 \mathrm{C}, \mathrm{CH}_{3}\right) ; 111.97-152.26$ (m, aromatic $\left.\mathrm{C}\right)$.

\subsection{Anticorrosion experiment}

2.3.1 Aluminum alloy specimen and corrosive solution preparation. The chemical composition ( $\mathrm{wt} \%$ ) of aluminum copper alloy (AA2219-T6) used for all experiments was: Al, Mn (0.32), Cu (6.48), Fe (0.23), Ti (0.06), Si (0.49), V (0.08), Zn (0.04), $\mathrm{Zr}$ (0.2). Dimensions of coupons used for weight loss experiments were $1.2 \times 1.1 \times 0.46 \mathrm{~cm}^{3}$ and a working electrode with 1 $\mathrm{cm}^{2}$ surface area was used for electrochemical measurements. Before performing the anticorrosion tests, the surface of the specimens of aluminum alloys were mechanically abraded with different grades of emery paper. Acetone was used for degreasing the coupons and double distilled water was used to wash them and then they were air-dried before dipping in the cell of corrosive or/and anticorrosive medium. Analytical grade $\mathrm{HCl}(37 \% \mathrm{w} / \mathrm{w})$ of preset normality was used for the formation of a corrosive solution of $0.1 \mathrm{M} \mathrm{HCl}$ with triple distilled water. To ensure the solubility of the compounds, their stock solution was prepared by adding $5 \%$ of DMF as a co-solvent. Different concentrations (50 ppm and $100 \mathrm{ppm}$ ) from stock solution were prepared in $0.1 \mathrm{M} \mathrm{HCl}$. In order to eliminate the effect of DMF, $0.1 \mathrm{M} \mathrm{HCl}$ solution containing 5\% DMF was used as a blank solution and the corrosion rate of aluminum was determined in this solution. The measurements were conducted in $30 \mathrm{~mL}$ of corrosive solution in the absence and presence of $50 \mathrm{ppm}$ and 100 ppm Schiff base inhibitors.

2.3.2 Weight loss experiment. Aluminum alloy specimens of dimensions $1.2 \times 1.1 \times 0.46 \mathrm{~cm}^{3}$ were used. These specimens were finely polished, dried, weighed and were used for the weight loss experiment. For that purpose, each aluminum alloy specimen was dipped in a $50 \mathrm{~mL}$ beaker containing $0.1 \mathrm{M} \mathrm{HCl}$ solution as per ASTM designation B686/B686M with and without addition of $50 \mathrm{ppm}$ and $100 \mathrm{ppm}$ of inhibitors for 6 hours at $298 \mathrm{~K}$. Afterwards, the strips which were inhibited in solutions of various inhibitor concentrations were taken out and the scales formed were removed with a bristle brush. The strips were thoroughly washed with double distilled water and liquid soap followed by rinsing with triple distilled water and finally with acetone. After the washing process, the substrates were dried and reweighed. ${ }^{36}$ Similarly, the corroded aluminum alloy substrate from the corrosive medium was taken out and cleaned with the same procedure mentioned before, but without scratching its surface, and reweighed. Loss in weight of specimen was determined by measuring the weight difference of the aluminum alloy substrates before and after immersion in the acidic medium. ${ }^{3}$

2.3.3 Electrochemical measurements. In order to measure the corrosion properties of aluminum alloy in $0.1 \mathrm{M} \mathrm{HCl} \mathrm{solu-}$ tion (blank) and for various concentrations of all Schiff base inhibitors, an electrochemical technique was employed. A standard three-electrode cell assembly was used for electrochemical measurements consisting of a Pyrex glass flask with a flat bottom and three openings for reference, working and counter electrodes. Aluminum alloy (AA2219-T6) was used as a working electrode. Saturated calomel electrode (SCE) and Pt wire were used as reference and counter electrodes, respectively. All the experiments were conducted in an atmospheric condition without stirring. After 30 minutes of immersion time of aluminum alloy in the solution of electrolyte with and without the addition of anticorrosive material, all the electrochemical measurements were conducted. The aluminum alloy substrate was dipped in the prepared solution until a stable value for open circuit potential (OCP) was obtained and measured. Gamry instrument interface $1010 \mathrm{e}$ potentiostat/galvanostat system was used to conduct the electrochemical measurements.

2.3.3.1 Electrochemical impedance spectroscopy. EIS was used for impedance measurements by applying an AC signal of amplitude $10 \mathrm{mV}$ in the frequency range from $100 \mathrm{kHz}$ to $0.02 \mathrm{~Hz}$. The investigation of the impedance spectra of Nyquist plot and fitting of the obtained results to equivalent circuits was done. The charge transfer resistance $\left(R_{\mathrm{ct}}\right)$ and double layer capacitance $\left(C_{\mathrm{dl}}\right)$ were calculated using the diameter of the semicircle obtained in the Nyquist plot. The inhibition efficiency percent $\eta_{\mathrm{EIS}}(\%)$ was calculated from $R_{\mathrm{ct}}$ values.

2.3.3.2 Potentiodynamic polarization. In Tafel polarization measurements, polarization curves were obtained by altering the electrode potential from -0.67 to $+0.67 \mathrm{mV}$ with a scan rate of $1.0 \mathrm{mV} \mathrm{s}^{-1}$ at open circuit potential. Cathodic and anodic curves having linear Tafel segments were extrapolated that yielded an intersection point to get corrosion current density $\left(i_{\text {corr }}\right)$ and corrosion potential $\left(E_{\text {corr }}\right)$. In order to confirm the reproducibility of the results, each experiment was repeated thrice and the most reproducible results were accepted and reported. Inhibition efficiency percentage $(\eta \%)$ was calculated by using relevant $i_{\text {corr }}$ values. 


\subsection{DFT calculation for theoretical models}

Quantum chemical calculations were performed using Gaussian (09) software. GaussView 5.0.8 was used to prepare the input file for the construction of organic Schiff base molecules. $^{37}$ Geometrical optimization of the title inhibitors in the gas phase without any constraints was performed using the DFT method, incorporating the B3LYP/3-21G++ basis set. B3LYP provides precise geometries and electronic properties for a broad range of organic compounds and has been previously used in examining the adsorption of anticorrosive molecules from solutions. ${ }^{38-40}$ The highest occupied molecular orbital energy $\left(E_{\text {Номо }}\right)$, the lowest unoccupied molecular orbital energy ( $\left.E_{\mathrm{LUMO}}\right)$, the energy gap $\left(\Delta E=E_{\mathrm{LUMO}}-E_{\mathrm{HOMO}}\right)$, the dipole moment $(\mu)$, electronegativity, softness, hardness, charge transfer parameter and Mulliken charge were calculated in quantum chemical calculations.

\subsection{Surface analysis}

FT-IR spectroscopic measurements were performed using a PerkinElmer System 2000 for confirmation of the adsorption of tested Schiff bases on the surface of aluminum substrate. Vibrational frequency data of pure Schiff bases and their adsorbed products on aluminum alloy AA2219-T6 after scratching from surface of aluminum were collected in the frequency range $4000-400 \mathrm{~cm}^{-1}$.

For morphological study, polished aluminum alloy AA2219T6 surface features $(1.2 \mathrm{~cm} \times 2.0 \mathrm{~cm} \times 0.46 \mathrm{~cm})$ were investigated before and after immersion in $0.1 \mathrm{M} \mathrm{HCl}$ in the absence and in the presence of inhibitors with different concentrations. The corroded surface morphology of all samples was observed using a SEM instrument (TESCAN VEGA3) operating at $12 \mathrm{kV}$ accelerating voltage.

\section{Results and discussion}

The UA, UB, and UC Schiff bases were obtained in good yields $(67-77 \%)$ by the condensation reaction of aniline with dialdehydes of different substitutions as depicted in Scheme 1. All the synthesized Schiff bases have good solubility in many common organic solvents like chloroform, DMF, DMSO, acetone and ethanol, but are partially soluble in methanol.

\subsection{Structure elucidation of synthesized compounds}

The FT-IR spectra of the Schiff base compounds were recorded in the $4000-400 \mathrm{~cm}^{-1}$ range. In all spectra of the organic Schiff base compounds, the disappearance of aldehydic carbonyl $\mathrm{C}=\mathrm{O}$ peak around $1680 \mathrm{~cm}^{-1}$ and appearance of azomethine $\mathrm{C}=\mathrm{N}$ band at $1585-1605 \mathrm{~cm}^{-1}$ indicated the formation of Schiff base linkage. The stretching vibration of ether $\mathrm{C}-\mathrm{O}-\mathrm{C}$ linkage appeared around $1209 \mathrm{~cm}^{-1}$. The stretching frequency around $2972-2891 \mathrm{~cm}^{-1}$ corresponds to aliphatic C-H; see Fig. S4 and S11 in the ESI. $\dagger$

The ${ }^{1} \mathrm{H}-\mathrm{NMR}$ spectra of UA, UB and UC were recorded at room temperature in $\mathrm{CDCl}_{3}$ solvent using TMS as a reference. The signal of azomethine protons appeared at 8.42, 8.41 and $8.51 \mathrm{ppm}$ for UA, UB and UC respectively. A singlet of methoxy protons for methoxy $\left(\mathrm{OCH}_{3}\right)$-substituted benzene ring of UB appeared at $3.98 \mathrm{ppm}$, whereas a triplet and quartet around 1.40 $(J=6.9)$ and $4.13(J=6.9)$ ppm, respectively, were observed in case of ethoxy-substituted Schiff base UC. Aromatic ring protons showed their characteristic signals in the range of 7.21-7.91 (m, $J=8.1)$ for $\mathbf{U A}, 7.20-7.67(\mathrm{~m}, J=8.4)$ for $\mathbf{U B}$ and $7.21-7.70(\mathrm{~m}, J$ $=8.4$ ) for UC. All Schiff bases displayed singlet for aliphatic protons $\left(\mathrm{CH}_{2}\right)$ at around 6.46, 6.59 and $5.96 \mathrm{ppm}$ for UA, UB and UC, respectively (Fig. S1, S5 and S8 in the ESI $\dagger$ ).

The ${ }^{13} \mathrm{C}$-NMR spectra of all tested Schiff bases were recorded at room temperature using $\mathrm{CDCl}_{3}$ and acetone as a solvent. In the ${ }^{13} \mathrm{C}-\mathrm{NMR}$ spectra of the compounds, the signal for azomethine $-\mathrm{HC}=\mathrm{N}$ - carbon was at 159.0, 159.69 and $159.54 \mathrm{ppm}$ for UA, UB and UC, respectively. The signal of $-\mathrm{CH}_{2}-$ carbon appeared at 101.02, 101.03, and $101.50 \mathrm{ppm}$ for UA, UB and UC, respectively. The methoxy $\left(\mathrm{OCH}_{3}\right)$ carbon showed a signal at $56.5 \mathrm{ppm}$ for $\mathbf{U B}$, and $\left(\mathrm{OCH}_{2}\right)$ and $\left(-\mathrm{CH}_{3}\right)$ signals appeared at 64.19 and $14.50 \mathrm{ppm}$, respectively, in the spectrum of UC. The aromatic carbon atoms displayed their signals around 116.48152.19 (UA), 116.48-152.19 (UB) and 111.97-152.26 (UC) ppm; see Fig. S2, S6 and S9 in the ESI. $\dagger$

The mass spectra of the Schiff bases (Fig. S3, S7 and S10 in the ESI $\dagger$ ) showed the molecular ion peak at $m / z=406,466$ and 494 for UA, UB, and UC, respectively, which matched with the formula weight of the investigated compounds.

\subsection{Corrosion inhibition measurements}

3.2.1 Weight loss measurements. The experimental data of weight loss $\Delta W$, percentage inhibition efficiency ( $\eta \%)$, corrosion rate $(\mathrm{CR})$ and surface coverage $(\theta)$ for AA2219-T6 in $0.1 \mathrm{M} \mathrm{HCl}$ in the absence and presence of the tested organic Schiff bases of different substitutions at $298 \mathrm{~K}$ are shown in Table 1 . The corrosion rate (CR) was calculated $\left(\mathrm{mg} \mathrm{cm}^{-2} \mathrm{~h}^{-1}\right)$ by the following eqn (1): ${ }^{41}$

$$
\mathrm{CR}=\frac{\Delta W}{A \times t}
$$

where $\Delta W$ is the average weight loss (mg), $t$ is the immersion time (h) and $A$ is the total area $\left(\mathrm{cm}^{2}\right)$ of the specimen. The inhibition efficiency (IE) was obtained through the corrosion rate. Eqn (2) was used to calculate percent inhibition efficiency $(\eta \%)$ :

$$
\eta \%=\left[\frac{\mathrm{CR}^{\circ}-\mathrm{CR}}{\mathrm{CR}^{\circ}}\right] \times 100
$$

where $\mathrm{CR}^{\circ}$ and $\mathrm{CR}$ are the corrosion rates of the aluminum alloy substrate in the absence and presence of different concentration of inhibitors, respectively. The degree of surface coverage $(\theta)$ was calculated through the following expression:

$$
\theta=\frac{\mathrm{CR}^{\circ}-\mathrm{CR}}{\mathrm{CR}^{\circ}}
$$

By adding the Schiff base inhibitors to acidic solution, the corrosion rate is reduced more prominently and the anticorrosive efficiency is increased (Table 1). These results suggest that these anticorrosive molecules are adsorbed successfully on the 


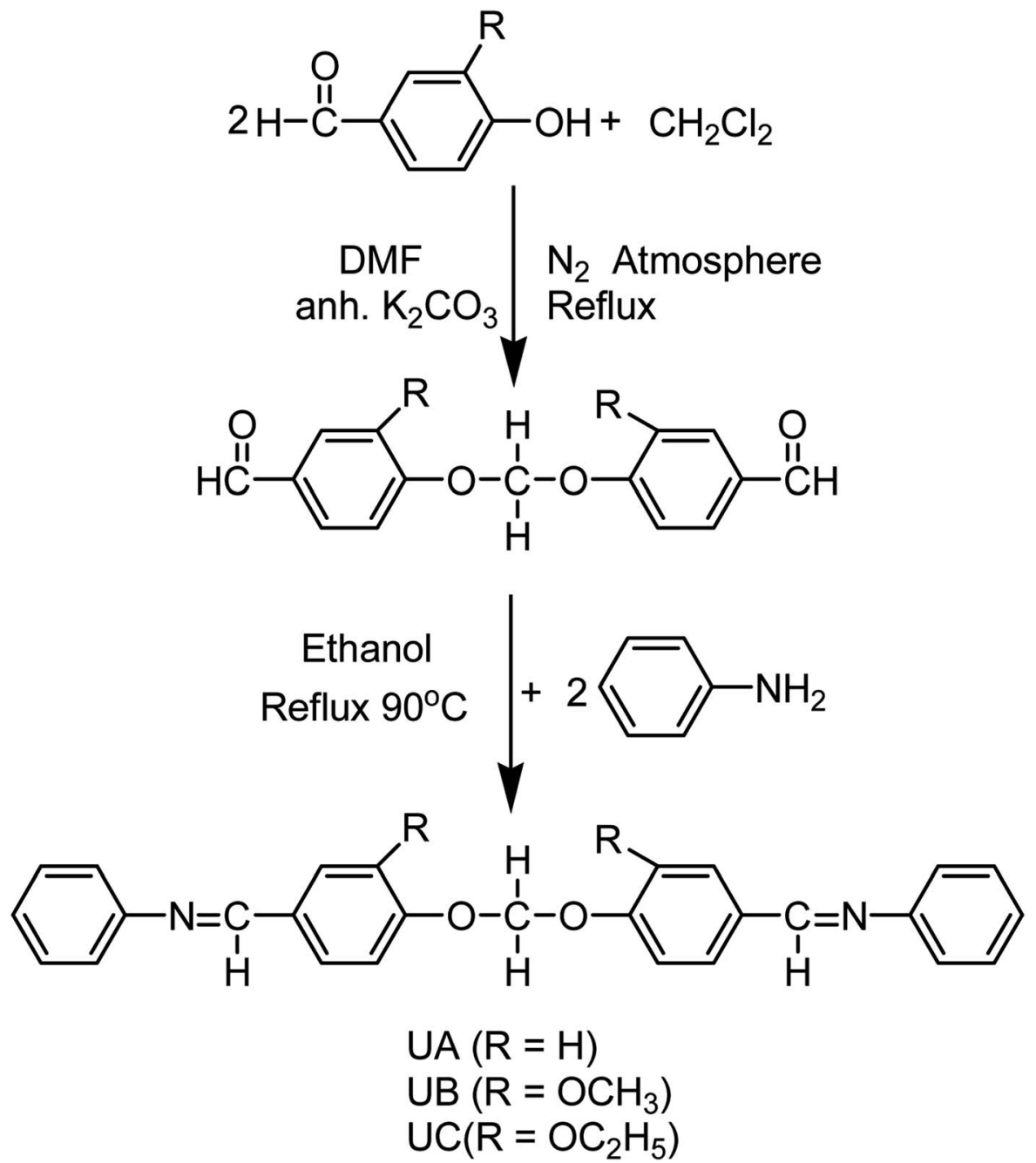

Scheme 1 Synthetic route of Schiff bases (UA, UB, UC).

aluminum surface restricting the corrosion process. At higher concentration, the inhibition performance is improved and this is evidence that more organic anticorrosive molecules are adsorbed on the aluminum surface and, thus, further surface coverage $(\theta)$. The weight loss experiments also indicate that corrosion rate decreased at all inhibitor concentrations in the order of $\mathbf{U C}>\mathbf{U B}>\mathbf{U A}$. This increase in efficiency of Schiff bases is due to the attachment of different substituents to benzene rings. The corrosion inhibition efficiency of an anticorrosive material is based on its capability to be adsorbed on a metal surface. The rate of corrosion was inhibited by all three Schiff bases as a result of their becoming adsorbed at the aluminum substrate via the lone pair of electrons on the heteroatoms, such as oxygen (-O-, $\left.-\mathrm{OCH}_{3},-\mathrm{OC}_{2} \mathrm{H}_{5}\right)$ and nitrogen $(>\mathrm{C}=\mathrm{N})$, and $\pi$ electrons in the benzene rings. The number of electrondonating moieties affects the adsorption affinity of the

Table 1 Weight loss parameters for AA2219-T6 in $0.1 \mathrm{M} \mathrm{HCl}$ in the absence and presence of various Schiff bases as corrosion inhibitors

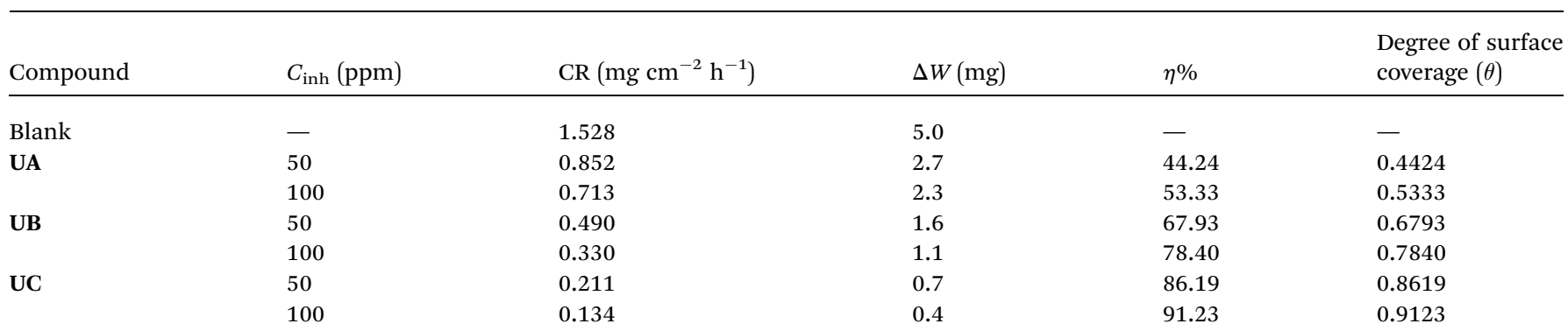




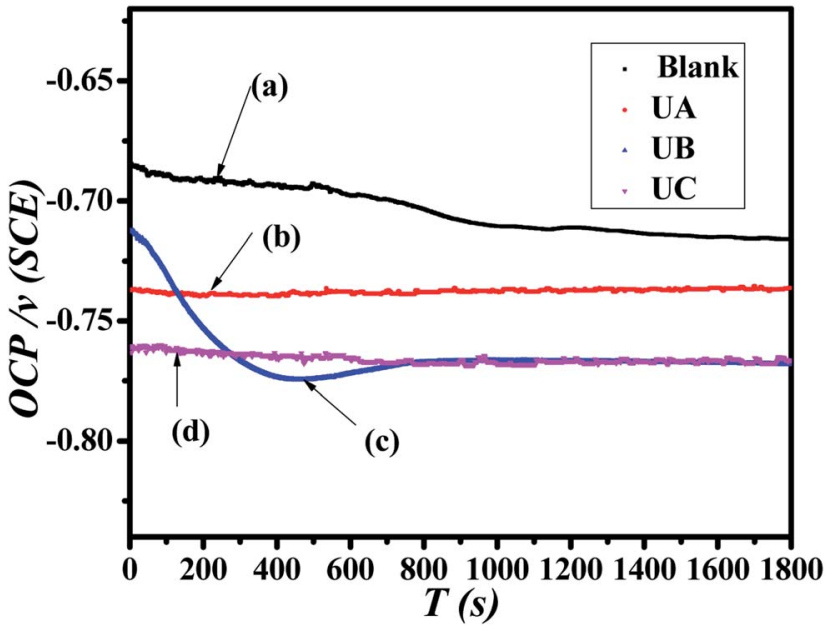

Fig. 1 Open circuit potential as a function of time for AA2219-T6 aluminum alloy in (a) $0.1 \mathrm{M} \mathrm{HCl}$ without inhibitor (blank) and with different inhibitors (b) UA, (c) UB and (d) UC.

inhibitor, i.e. the adsorption would be stronger with functional groups having electron-donating property and corrosion inhibition would be higher. Thus, in the present case, UB has much higher protection ability than UA due to the presence of electron-donating $\mathrm{OCH}_{3}$ group and $\mathbf{U C}$ has a maximum protection ability due to the presence of electron-donating $\mathrm{OC}_{2} \mathrm{H}_{5}$ group..$^{4,42}$

3.2.2 Monitoring open circuit potential. Prior to each electrochemical measurement, the working electrodes were immersed in $0.1 \mathrm{M} \mathrm{HCl}$ for $30 \mathrm{~min}$ to attain a stable value of open circuit potential (OCP) and define domains of corrosion. ${ }^{43}$ Fig. 1 shows the plots of OCP vs. time $(t)$ for AA2219-T6 in $0.1 \mathrm{M}$ $\mathrm{HCl}$ solution without and with inhibitor. In the case of $\mathbf{U B}$, the OCP moves faster towards a negative direction up to $300 \mathrm{~s}$ and then it attains a steady value for the rest of the experimental time. The OCP values for the UB inhibitor solution transfer towards a more negative potential as compared to the blank solution which may be ascribed to the formation of a protective film on the surface of the electrode. ${ }^{44}$ This was inferred from the results shown in Fig. 1, which shows that OCP values of the aluminum corrosion in the presence of Schiff base UB mostly are more negative ${ }^{45}$ than those of the blank. For comparison, an overlay of all the inhibitors is given in Fig. 1. This suggested that the OCP values of aluminum alloy corrosion in the presence of the Schiff base inhibitors are more negative as compared to the OCP value in the absence of inhibitor suggesting a predominantly cathodic character. UB and UC gave more negative OCP values than UA because of the electron-donating functional groups $\mathrm{OCH}_{3}$ and $\mathrm{OC}_{2} \mathrm{H}_{5}$ attached to the aromatic rings of $\mathbf{U B}$ and UC compounds, respectively.

3.2.3 Electrochemical impedance spectroscopy. EIS is an efficient method for studying anticorrosive phenomena. ${ }^{46}$ EIS results were obtained for the synthesized Schiff bases UA, UB and UC at various concentrations, for anticorrosive studies using the aluminum substrate AA2219-T6 in $0.1 \mathrm{M} \mathrm{HCl}$ at open circuit potential. Impedance studies provide a clear illustration of the corrosion inhibition kinetics of metallic substrates in terms of Bode and Nyquist plots $\left(Z_{\text {real }} v s\right.$. $\left.Z_{\text {imag }}\right)$. Nyquist plots are given in Fig. 2. It is obvious from the Nyquist plots that with the addition of anticorrosive Schiff bases, the impedance response has changed. Inhibition efficiencies at different
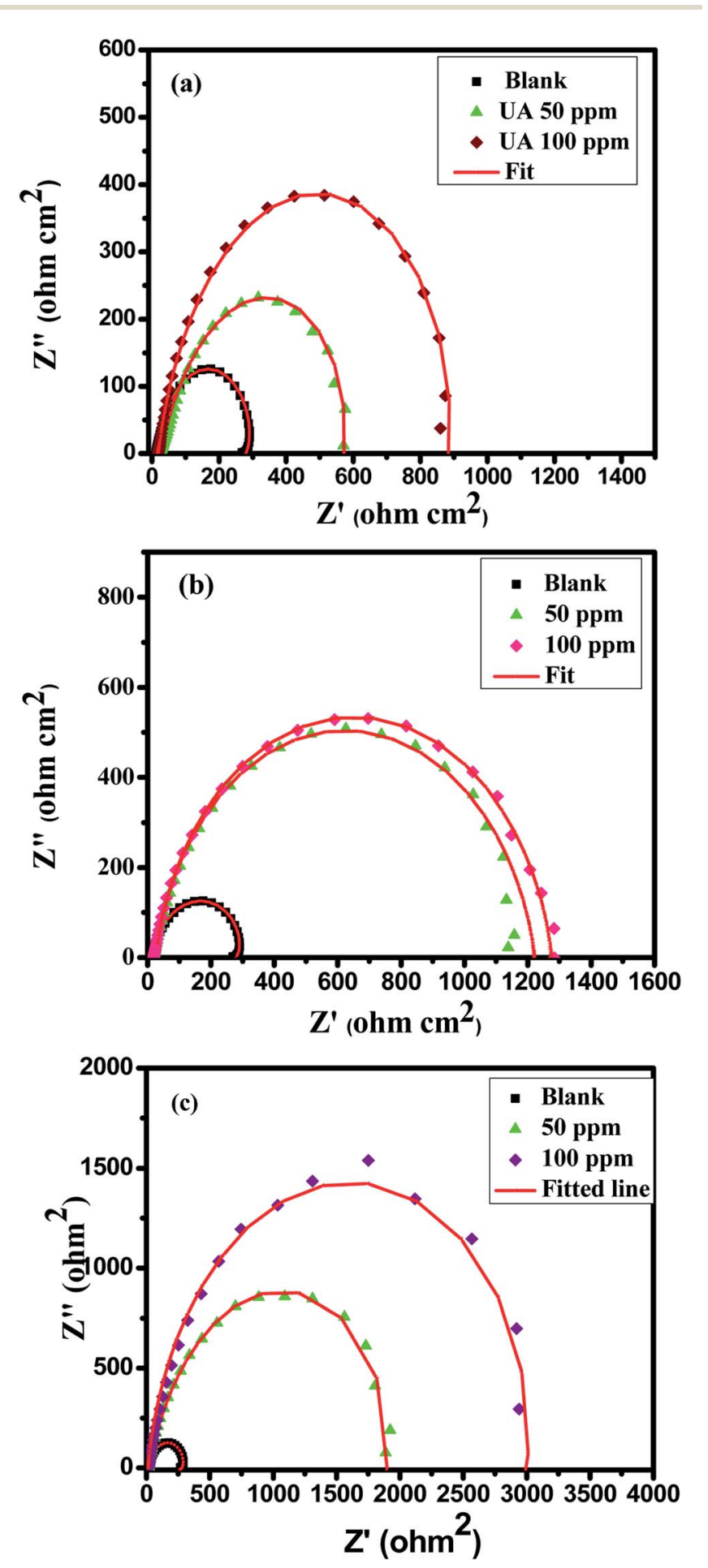

Fig. 2 Nyquist plots for aluminum alloy AA2219-T6 in $0.1 \mathrm{M} \mathrm{HCl}$ solution in the absence and presence of Schiff bases (a) UA, (b) UB and (c) UC of 50 and $100 \mathrm{ppm}$ concentrations with their model-fitted overlay. 
concentrations were evaluated from the charge transfer resistance $R_{\text {ct }}$ by using the following eqn (4): ${ }^{47}$

$$
\mathrm{IE} \%=\left[\frac{R_{\mathrm{ct}}-R_{\mathrm{ct}}^{\circ}}{R_{\mathrm{ct}}}\right] \times 100
$$

Nyquist plots of all the inhibitors exhibited a semicircleshaped capacitive loop in the high-frequency region and an inductive loop in the low-frequency area as shown in Fig. 2(a-c). The semicircle is indicative of a barrier layer formation of the Schiff bases on the aluminum alloy surface, therefore elucidating the charge transfer resistance related with the corrosion activity and the behavior of the electrical double layer. Stabilization of intermediates formed during the corrosion process may result in the formation of an inductive loop; ${ }^{\mathbf{4 8 , 4 9}}$ however, the mechanism is still unclear. Deviation from the ideal semicircle is generally ascribed to frequency scattering as well as non-homogeneity, roughness of substrate surface, mass transport process and resulting adsorption.

Table 2 shows that the charge-transfer values are increased and there is a corresponding decrease in the values of double layer capacitance on increasing the concentration of all three inhibitors. With an increase in concentration of the tested Schiff bases, the inhibition efficiency increases. The decrease in CPE $\left(C_{\mathrm{dl}}\right)$ values can be assigned to a decrease in local dielectric constant and/or an increase in electrical double layer thickness, suggesting that the inhibitor molecules are adsorbed at the metal/solution boundary. ${ }^{\mathbf{5 0 , 5 1}}$ This may be due to the replacement of molecules of water by the anticorrosive molecules at the metal/solution interface.

Nyquist plots were comprehended further by fitting the experimental data to a simple equivalent circuit model as shown in Fig. 3a and b, which consists of the charge transfer resistance $\left(R_{\mathrm{ct}}\right)$, solution resistance $\left(R_{\mathrm{s}}\right)$, constant phase element (CPE), inductor and its corresponding resistance. CPE is used instead of an ideal capacitor (for ideal cases, the CPE is equal to a capacitor when $n=1$ ) in order to account for the non-ideal behavior of the system. ${ }^{52}$ The Nyquist plots of aluminum alloy in the absence and presence of substituted Schiff bases with different concentrations are shown in Fig. 2(a-c).

The extent of corrosion of aluminum was perceived to decrease with an increase in the inhibitor concentration which is evidenced by the increased charge transfer resistance values

Table 2 Electrochemical parameters extracted from the equivalent circuit fits for aluminum alloy in the absence and presence of the inhibitors

\begin{tabular}{llccll}
\hline Code & Conc. $(\mathrm{ppm})$ & $R_{\mathrm{ct}}\left(\Omega \mathrm{cm}^{2}\right)$ & $C_{\mathrm{dl}}(\mu \mathrm{F})$ & $R_{\mathrm{s}}\left(\Omega \mathrm{cm}^{2}\right)$ & $\eta \%$ \\
\hline Blank & - & 317.8 & 398.29 & 3.60 & - \\
UA & 50 & 723.0 & 352.54 & 6.03 & 6.04 \\
& 100 & 998.0 & 221.28 & 8.19 & 8.15 \\
UB & 50 & 1227 & 210.68 & 8.57 & 3.93 \\
& 100 & 1250 & 202.52 & 6.55 & 4.57 \\
UC & 50 & 2740 & 92.39 & 0.00 & 8.40 \\
& 100 & 3750 & 67.0 & 5.01 & 1.52
\end{tabular}
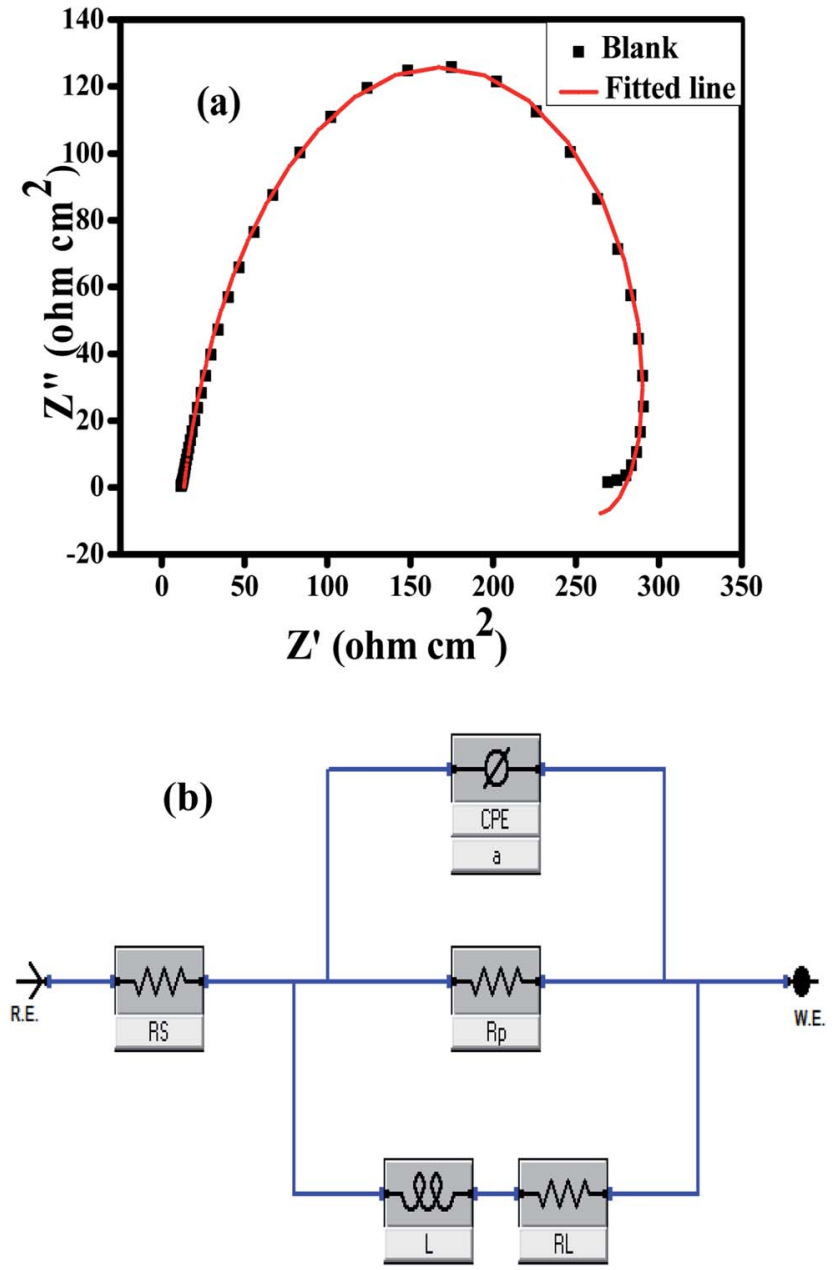

Fig. 3 (a) Blank fitted Nyquist plot and (b) suggested equivalent circuit model used to measure the impedance for the investigated Schiff bases.

for these anticorrosive compounds. The pronounced increase in $R_{\text {ct }}$ values is imputed to the formation of an insulating protective film at the metal/solution interface. Hence, higher $R_{\mathrm{ct}}$ values are associated with a slower-corroding system. ${ }^{7}$ The decrease in CPE $\left(C_{\mathrm{dl}}\right)$ values can be assigned to a decrease in the local dielectric constant and/or an increase in the electrical double layer thickness, suggesting that the inhibitor molecules are adsorbed at the metal/solution boundary. ${ }^{50,51}$ A comparison of the capacitive loops of UA, UB and UC indicates that ethoxy and methoxy substitutions directly affect the anticorrosion efficiency. From the inhibition efficiencies it is assessed that there is superior inhibition performance of UB and UC for aluminum corrosion in $0.1 \mathrm{M} \mathrm{HCl}$ due to the presence of electron-donating methoxy $\left(-\mathrm{OCH}_{3}\right)$ and ethoxy $\left(-\mathrm{OC}_{2} \mathrm{H}_{5}\right)$ groups. The EIS results obtained are very much consistent with the weight loss measurement results.

The following eqn (5) is used to calculate double layer capacitance $C_{\mathrm{dl}}$ :

$$
C_{\mathrm{dl}}=\frac{1}{2 \pi f_{\mathrm{m}} R}
$$


where $f_{\mathrm{m}}$ is the maximum frequency at the highest value of the imaginary component of the Nyquist plot and $R$ is the charge transfer resistance.

3.2.4 Potentiodynamic polarization measurements. Fig. 4 presents the potentiodynamic polarization curves (Tafel plots) of AA2219-T6 aluminum alloy in $0.1 \mathrm{M} \mathrm{HCl}$ solution in the absence and presence of UA, UB and UC inhibitors. Tafel fit extrapolation was used to extract electrochemical parameters such as corrosion potential ( $\left.E_{\text {corr }}\right)$, corrosion current density $\left(i_{\text {corr }}\right)$, and cathodic and anodic Tafel slopes $\left(\beta_{\mathrm{c}}\right.$ and $\left.\beta_{\mathrm{a}}\right)$. The results from potentiodynamic polarization measurements are summarized in Table 3. The inhibition efficiency (IE\%) and surface coverage $(\theta)$ were also calculated according to eqn (6) and $(7)^{53}$ and the obtained values are presented in Table 3 :

$$
\begin{gathered}
\theta=\frac{i_{\text {corr }}^{\circ}-i_{\text {corr }}}{i_{\text {corr }}^{\circ}} \\
\eta \%=\left[\frac{i_{\text {corr }}^{\circ}-i_{\text {corr }}^{\circ}}{i_{\text {corr }}^{\circ}}\right] \times 100
\end{gathered}
$$

where $i_{\text {corr }}^{\circ}$ and $i_{\text {corr }}$ are the values of current densities without and with inhibitors, respectively.

Adsorption of anticorrosive materials on a metal surface is usually associated with the depletion of the number of active reaction sites, as they are blocked by the adsorbate. During the electrochemical reaction, fewer active sites on the metal surface yields a lower metal dissolution and/or evolution of hydrogen. Inhibitors can be categorized as cathodic, anodic or mixed type according to $E_{\text {corr }}$ values. When the $E_{\text {corr }}$ values between blank and inhibited solutions are $>85 \mathrm{mV}$, the inhibitor molecules are of anodic or cathodic type. As shown in Table 3, adding anticorrosive compounds to the solution changes both anodic and cathodic slopes compared to those of blank solutions. $E_{\text {corr }}$ values in the presence of Schiff base inhibitors are shifted in the negative direction; this effect is more prominent at higher concentration. This shift in $E_{\text {corr }}$ is from -2 to $-80 \mathrm{mV}$ which suggests that all studied organic Schiff bases UA, UB, and UC act as mixed-type inhibitors but predominantly cathodic. ${ }^{54}$ Furthermore, the corrosion current density is decreased and the inhibition efficiency is increased as the inhibitor concentration is increased for all the Schiff bases (inhibitors). The main criterion in determining the inhibition efficiency of an anticorrosive material is the corrosion current density $\left(I_{\text {corr }}\right)$. The corrosion current density is lower in the solution containing UC than that in the solution containing UB, which in turn is slightly lower than that in the solution containing UA, for similar concentration, in agreement with our impedance results. This suggests that the inhibitor molecules are adsorbed at the $\mathrm{Al} /$ solution interface where the adsorbed molecules mechanically screen the coated part of the surface of metal from the action of the corrosive material. The inhibition efficiency values of the examined organic Schiff bases follow the order UC $>$ UB $>$ UA. The electron-donating methoxy and ethoxy group in UC and UB, respectively, could potentially contribute to a better corrosion protection efficiency than that of UA.

3.2.5 Adsorption isotherm. It has been presumed that organic inhibitors manifest their inhibition via the adsorption of
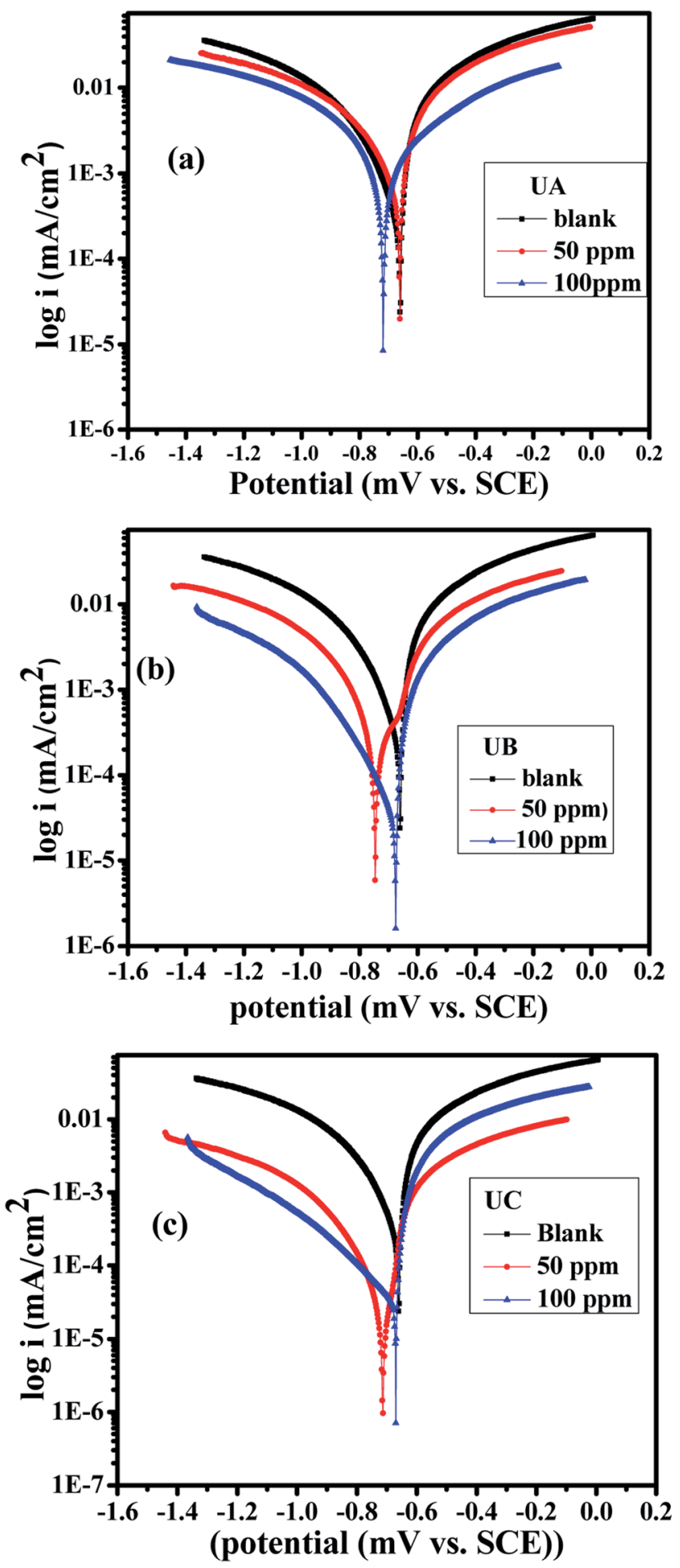

Fig. 4 Tafel polarization curves for aluminum in $0.1 \mathrm{M} \mathrm{HCl}$ in the absence and presence of various concentrations of Schiff base inhibitors (a) UA, (b) UB and (c) UC.

the anticorrosive material on to the surface of a metal. Chemical structures of organic compounds, surface charge and nature of metal, molecular charge distribution and type of aggressive media are factors affecting inhibitors in adsorption processes. ${ }^{\mathbf{1 0}}$ 
Table 3 Electrochemical parameters extracted from the potentiodynamic polarization curves for corrosion of aluminum alloy in $0.1 \mathrm{M} \mathrm{HCl}$ in the presence and absence of Schiff bases at $298 \mathrm{~K}$ (results from Fig. 4)

\begin{tabular}{|c|c|c|c|c|c|c|c|}
\hline Blank & - & -678.0 & 18.59 & 1.200 & 1.8 & - & - \\
\hline UA & 100 & -700.5 & 8.980 & 1.467 & 1.335 & 0.5169 & 51.7 \\
\hline \multirow[t]{2}{*}{ UB } & 50 & -759.9 & 5.723 & 0.653 & 1.303 & 0.6921 & 69.2 \\
\hline & 100 & -762.0 & 2.86 & 0.950 & 0.816 & 0.8461 & 84.6 \\
\hline
\end{tabular}

With an increase in the concentration of the investigated Schiff bases, the inhibition efficiency is increased. This fact can be explained by the adsorption of these Schiff bases on the aluminum surface. Examining the adsorption isotherm is helpful for probing these interactions and the inhibitor adsorption mechanism. ${ }^{55}$ Adsorption isotherms of UA, UB, and UC on AA2219-T6 aluminum alloy by their surface coverage $(\theta)$ as a function of anticorrosive compound concentration in $0.1 \mathrm{M}$ HCl solution $\left(C_{\text {inh }}\right)$ are shown in Fig. 5 . The plots indicate that all inhibitors UA, UB and UC follow a linear Langmuir isotherm tendency, as straight lines were yielded with a correlation coefficient of approximately 1 . The Langmuir isotherm is given by the following eqn (8): ${ }^{56}$

$$
\frac{C_{\mathrm{inh}}}{\theta}=\frac{1}{K_{\mathrm{ads}}}+C_{\mathrm{inh}}
$$

Here, $K_{\text {ads }}$ is the equilibrium constant for adsorption and $\theta$ is calculated from potentiodynamic polarization measurements. The equilibrium constant of adsorption process $K_{\text {ads }}$ is related to $\Delta G_{\text {ads }}^{\circ}$, the free adsorption energy, through eqn (9): ${ }^{55,57}$

$$
\Delta G_{\mathrm{ads}}^{\circ}=-R T \ln \left(55.5 K_{\mathrm{ads}}\right)
$$

where $R$ is the gas constant, $T$ is the temperature and 55.5 is the molar concentration of water in solution (in mol $\mathrm{L}^{-1}$ ). Anticorrosive compounds are presumed to adsorb on a solid surface with a series of prominent binding sites. As all sites are identical, therefore each site can attach to only one inhibitor.

Thermodynamic parameters obtained from Langmuir adsorption isotherms for the studied compounds are given in Table 4 . It is obvious from the table that high values of $K_{\text {ads }}$ reflect the strong interaction between the aluminum and anticorrosive compounds. In the literature it was reported that high $K_{\text {ads }}$ values ( $>\sim 100 \mathrm{M}^{-1}$ ) relate to the stronger and more stable adsorbed layer formation on a metal substrate surface. ${ }^{\mathbf{8 5 8}}$ Generally, a value of $\Delta G_{\text {ads }}^{\circ}$ of around or higher (more negative) than $-40 \mathrm{~kJ} \mathrm{~mol}^{-1}$ involves charge sharing between the compounds and metal (chemisorption). ${ }^{57}$ In the present work, the calculated values of $\Delta G_{\text {ads }}^{\circ}$ for studied Schiff base compounds UA, UB and UC are $40.89 \mathrm{~kJ} \mathrm{~mol}^{-1}, 39.70 \mathrm{~kJ} \mathrm{~mol}^{-1}$ and $39.74 \mathrm{~kJ} \mathrm{~mol}^{-1}$, respectively. This is an indication of dominant chemisorption, but the physisorption contribution should also be considered due to the possibility of formation of protonated Schiff bases which can interact electrostatically with surface of charged metal substrate. To understand further the adsorption mechanism of the investigated molecules (inhibitors), quantum chemical calculation was performed.

\subsection{Quantum chemical calculations}

The spatial molecular structure of an organic anticorrosive compound as well as its electronic structure play a vital role in the inhibition efficiency of the compound. The chemical reactivities of organic compounds are dependent on the frontier molecular orbitals (FMO), consisting of the highest occupied molecular orbital, HOMO, and the lowest unoccupied molecular orbital, LUMO. ${ }^{6}$ In Fig. 6, we show the HOMO and LUMO of UA, UB, and UC in their optimized molecular structures

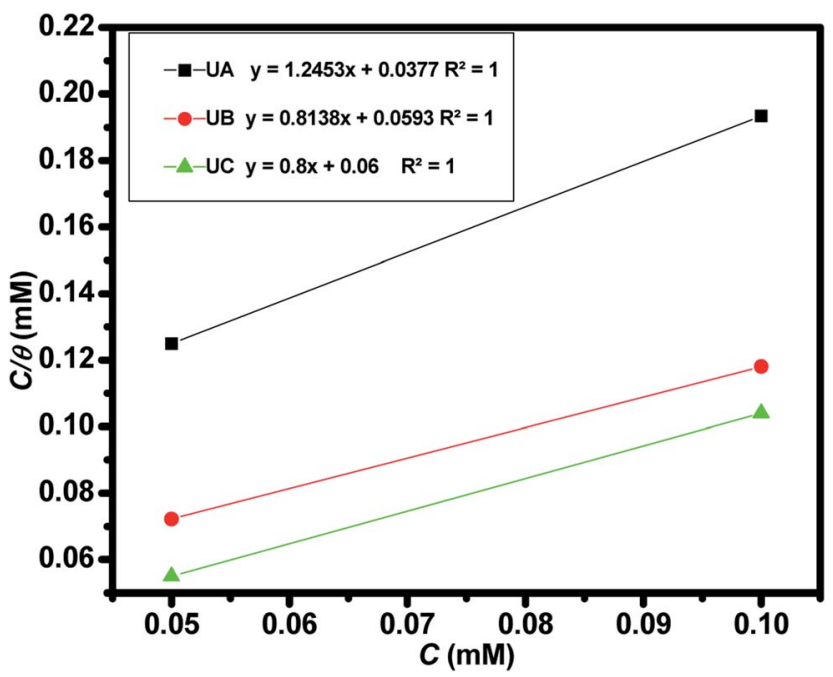

Fig. 5 Langmuir adsorption isotherm plots for the investigated Schiff base corrosion inhibitors.

Table 4 Adsorption equilibrium constant $\left(K_{\text {ads }}\right)$ and adsorption free energy $\left(\Delta G_{\text {ads }}^{\circ}\right)$ for Schiff bases

\begin{tabular}{lll}
\hline Compound & $K_{\text {ads }}\left(\times 10^{4} \mathrm{M}^{-1}\right)$ & $-\Delta G_{\mathrm{ads}}^{\circ}\left(\mathrm{kJ} \mathrm{mol}^{-1}\right)$ \\
\hline UA & 2.6525 & 40.89 \\
UB & 1.6834 & 39.76 \\
UC & 1.6666 & 39.74
\end{tabular}




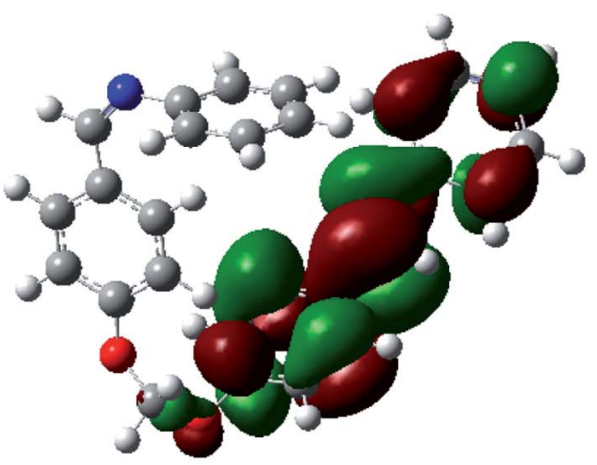

LUMO

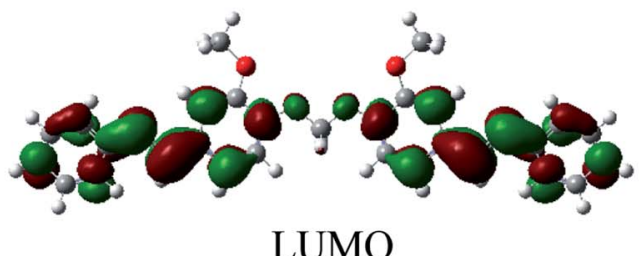

LUMO

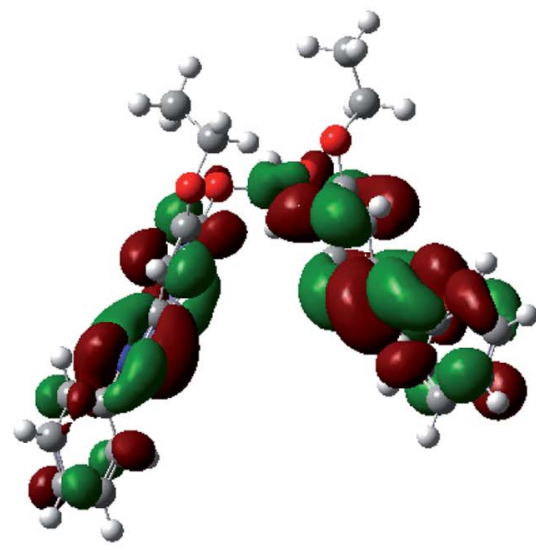

LUMO
(UB)

(UA)

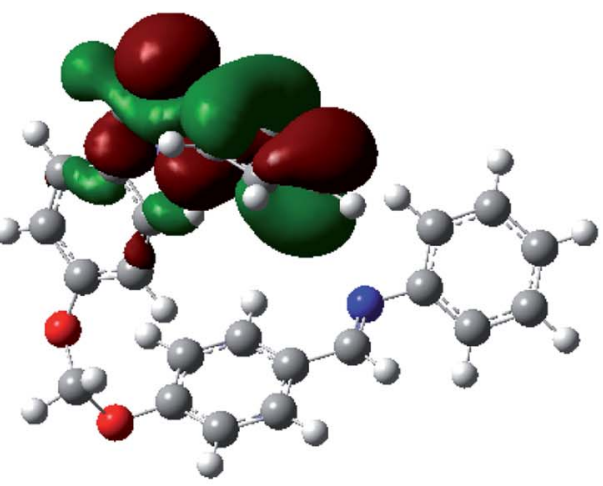

HOMO

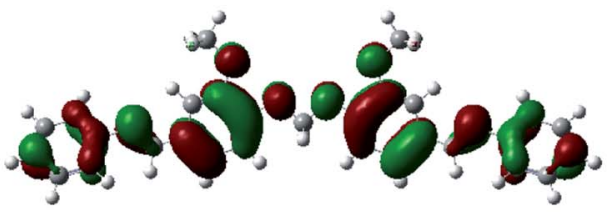

HOMO

Fig. 6 Highest occupied molecular orbital (HOMO) and lowest unoccupied molecular orbital (LUMO) for UA, UB, and UC.

obtained using the DFT functional B3LYP method with the 3$21 \mathrm{G}$ basis set.

Table 5 shows the calculated quantum parameters for all the Schiff base inhibitors. The influence of $E_{\text {HOMO }}$ and $E_{\text {LUMO }}$ of inhibitors, which show the ability of the anticorrosive compounds to react with a substrate, is discussed as follows. Electron-donating ability of a molecule to a suitable acceptor with empty molecular orbitals (p orbital in aluminum) is indicated through $E_{\text {номо }}{ }^{37,55}$ Therefore, high values of $E_{\text {Hомо }}$ can facilitate the adsorption and increase the inhibition efficiency (IE\%). Similarly, $E_{\text {Lumo }}$ indicates the electron-accepting ability of the anticorrosive compound. The corrosion inhibition efficiency is decreased as a consequence of aggregation of electrons on the surface due to the repulsion of the electronegative
Table 5 Quantum chemical parameters obtained using the B3LYP method with a 3-21 basis set for the Schiff bases

\begin{tabular}{llll}
\hline & \multicolumn{2}{l}{ Schiff base inhibitors } \\
\cline { 2 - 4 } Quantum parameter & UA & UB & UC \\
\hline$E_{\text {HOMO }}(\mathrm{eV})$ & -5.5711 & -5.5088 & -5.4935 \\
$E_{\text {LUMO }}(\mathrm{eV})$ & -1.6551 & -1.6609 & -1.6709 \\
$\Delta E(\mathrm{eV})$ & 3.9160 & 3.8478 & 3.8226 \\
$\mu(\mathrm{eV})$ & 2.6582 & 1.9597 & 4.84 \\
$I(\mathrm{eV})$ & 5.57118 & 5.50881 & 5.49359 \\
$A(\mathrm{eV})$ & 1.6551 & 1.6609 & 1.6709 \\
$\chi(\mathrm{eV})$ & 3.61314 & 3.58488 & 3.58227 \\
$\eta(\mathrm{eV})$ & 1.95804 & 1.92393 & 1.91132 \\
$\sigma$ & 0.5107 & 0.5197 & 0.5231 \\
$\Delta N$ & 1.747 & 1.771 & 1.782085
\end{tabular}


inhibitor from the metal surface. In the present study, the lower values of $E_{\mathrm{Lumo}}$ indicate that the Schiff base inhibitors can easily gain free electrons from the metal. ${ }^{\mathbf{4 0}}$

Energy gap $\left(\Delta E=E_{\mathrm{LUMO}}-E_{\mathrm{HOMO}}\right)$ is a vital parameter that indicates the activity of an anticorrosive compound. Low values of $\Delta E$ provide high inhibition effectiveness, because less excitation energy is required to remove electrons from the last occupied orbital and the inhibitor adsorbs more promptly. ${ }^{39}$ According to Table 5 , UC has the lowest $\Delta E$ value compared to UA and UB. UC also has the highest $E_{\text {HOMO }}$ and lowest $E_{\text {LUMO }}$ values as compared to UA and UB. Although all compounds show comparable inhibition efficiencies, UC and UB are more efficient inhibitors because of the presence of electron-donating groups (ethoxy and methoxy). The HOMO of anticorrosive Schiff bases appears mainly in the proximity of nitrogen and oxygen atoms. These atomic sites assist the adsorption of the studied Schiff bases on the aluminum alloy surface. Mulliken charge population analysis also leads to the same conclusion of charge distribution over all the organic Schiff bases. ${ }^{39}$ As shown in Fig. 7, the highest negative charge densities are placed on oxygen and nitrogen atoms, which are responsible for a strong bond between Schiff base and metal substrate surface.

The HOMO and LUMO energies of the anticorrosive molecules are associated with ionization potential $(I)$ and electron affinity $(A)$, respectively, and are obtained from the following equations:

$$
\begin{aligned}
& I=-E_{\text {HOMO }} \\
& A=-E_{\text {LUMO }}
\end{aligned}
$$

The adiabatic global hardness $(\eta)$ and adiabatic electronegativity $(\chi)$ were computed from the following equations:

$$
\begin{gathered}
\eta=\frac{I-A}{2} \\
\chi=\frac{(I+A)}{2}
\end{gathered}
$$

The reciprocal of the hardness is known as the softness:

$$
\sigma=\frac{1}{\eta}
$$

Absolute values of $\sigma$ and $\eta$ indicate molecular stability and reactivity.

The charge transferred $(\Delta N)$ from Schiff base inhibitor to aluminum metal was determined by the following expression: ${ }^{38}$

$$
\Delta N=\frac{\left(\chi_{\mathrm{Al}}-\chi_{\mathrm{inh}}\right)}{2\left(\eta_{\mathrm{Al}}+\eta_{\mathrm{inh}}\right)}
$$

From this study the theoretical value of bulk aluminum electronegativity is $\chi_{\mathrm{Al}}=3.23 \mathrm{eV}$ based on Pearson. ${ }^{59} \mathrm{~A}$ global hardness of $\eta_{\mathrm{Al}}=0$, by assuming that for a metallic bulk $I=A$, because they are softer than the neutral metallic atom. Previously it was reported that if $\Delta N<3.6$, the inhibitor efficiency is

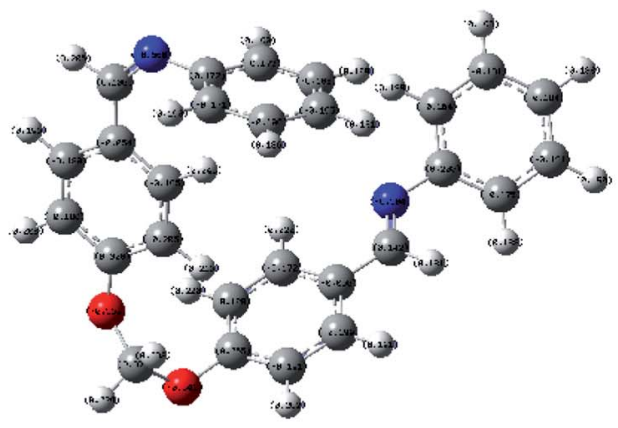

(UA)

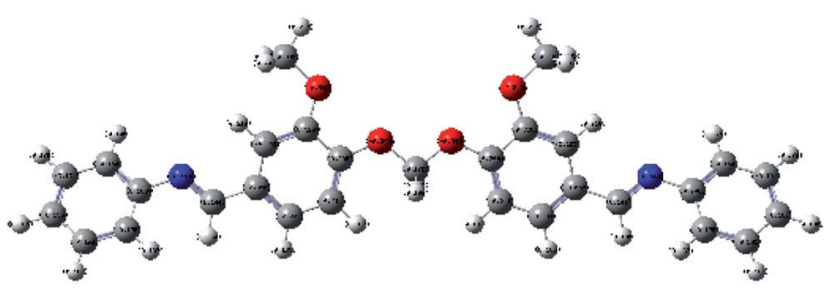

(UB)

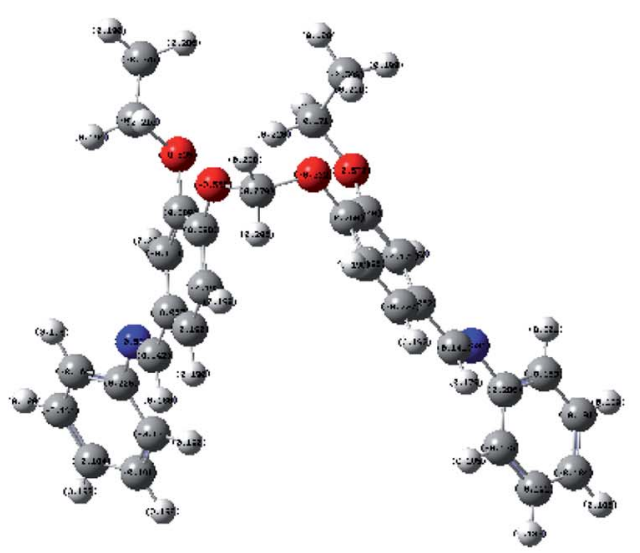

(UC)

Fig. 7 Distribution of Mulliken charges in UA, UB, UC Schiff bases.

enhanced by an increase in the ability of inhibitor to donate electrons to the metal substrate surface. ${ }^{38}$

\subsection{Surface analysis}

3.4.1 FT-IR spectroscopy. FT-IR spectroscopy was performed on the post-corrosion surfaces to get deeper insights into the formation of various adsorption products on the surface of aluminum alloy AA2219-T6 in acidic medium. In addition, it was used to further confirm the adsorption of Schiff bases as anticorrosive materials and the functional groups taking part in the adsorption mechanisms and to investigate the type of bond formed by the adsorbed anticorrosive materials. Table 6 presents the FT-IR vibrational frequencies of a representative Schiff base and those of the corrosion products of aluminum alloy inhibited by it. Prominent functional groups identified in the FT-IR spectrum of include $\mathrm{C}=\mathrm{N}, \mathrm{Ar}-\mathrm{CH},-\mathrm{CH}_{2}^{-}$ 
Table 6 FT-IR stretching frequencies of representative Schiff base and the corrosion product of aluminum in the presence of Schiff base (UB)

\begin{tabular}{lll}
$\begin{array}{l}\text { Inhibitor before } \\
\text { adsorption }\end{array}$ & $\begin{array}{l}\text { Corrosion product } \\
\text { of aluminum }\end{array}$ & Functional group/assignment \\
\hline 3054 & 3050 & Aromatic-C-H \\
2972 & 2930 & C-H aliphatic \\
1585 & 1575 & C=N stretch \\
1572 & 1573 & C-C stretch \\
1373 & 1371 & C-H rocking \\
1447 & 1461 & C-N stretch \\
1249 & 1245 & C-O-C
\end{tabular}

, C-O-C, C-C, C-H and C-N. However, when the Schiff base was used as a corrosion inhibitor for aluminum in acidic medium, some functional group bands were shifted to the right or left while some were absent as shown in Table 6 and Fig. S12 in the ESI. $\uparrow$ Shift in frequency of FT-IR absorption and decrease in the peak intensities revealed that there is an interaction between the inhibitor and the aluminum alloy surface. The stretching vibrations of $\mathrm{C}=\mathrm{N}$ and $\mathrm{C}-\mathrm{O}-\mathrm{C}$ are slightly shifted towards lower frequencies, indicating interactions between the unshared pair of electrons on the nitrogen and oxygen atoms and aluminum atoms. This provides evidence for improved retardation of aluminum alloy corrosion. ${ }^{45}$

3.4.2 SEM analysis. The effect of corrosion inhibitors on the surface of AA2219-T6 aluminum alloy in both the absence and presence of Schiff bases was investigated by SEM. SEM images clearly depicting both the corroded and inhibited surfaces with different magnification levels are shown in Fig. 8 [(a)i, (a)c]-[(c)i, (c)c]. After immersion in the blank $0.1 \mathrm{M} \mathrm{HCl}$ solution for $6 \mathrm{~h}$, the uniform aluminum alloy surface is

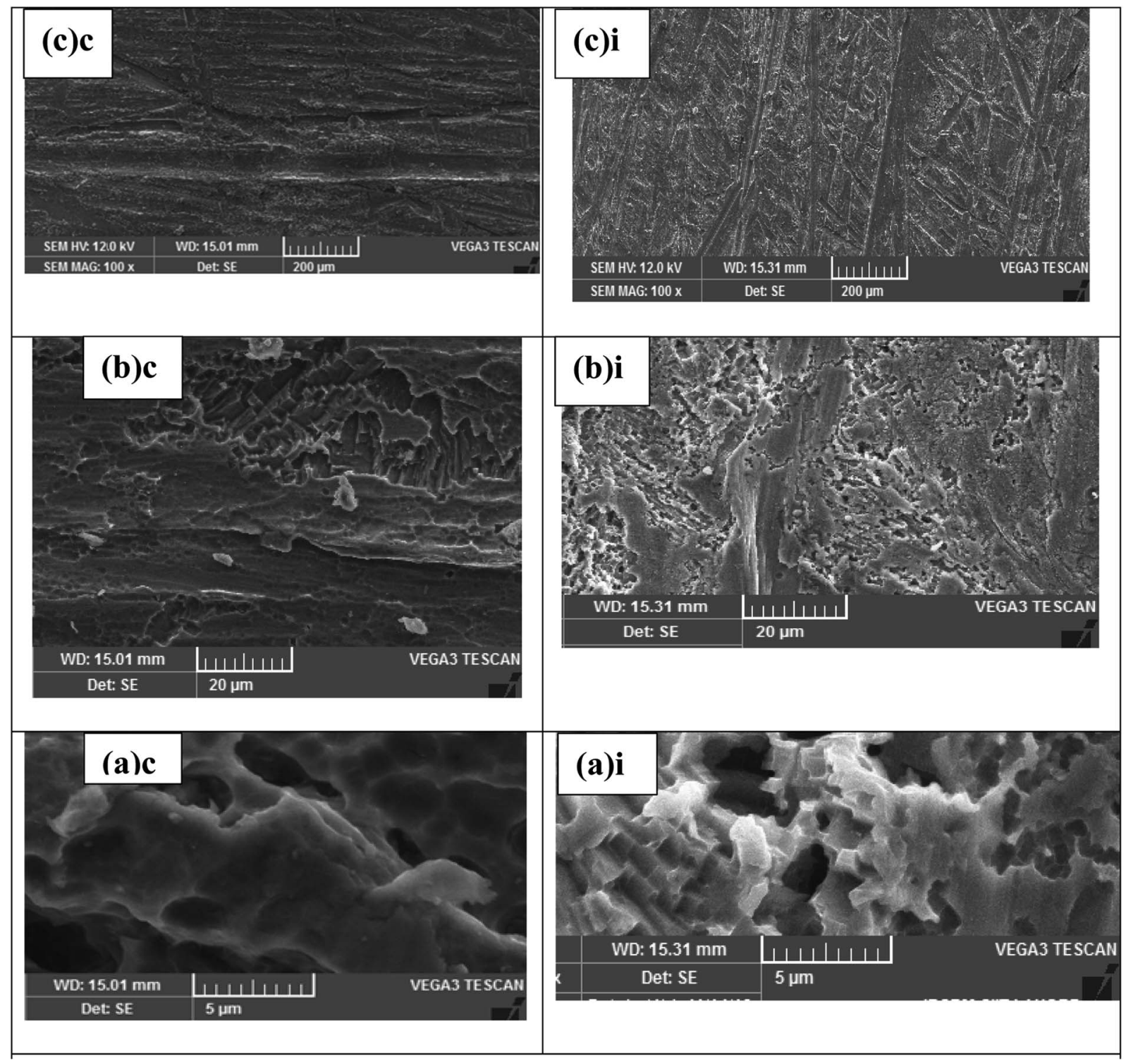

Fig. 8 SEM micrographs of the aluminum alloy surface without and with UA Schiff base inhibitor: [(a)c] corroded surface at $5 \mu$ m, [(a)i] inhibited surface at $5 \mu \mathrm{m},[(\mathrm{b}) \mathrm{c}]$ corroded surface at $20 \mu \mathrm{m},[(\mathrm{b}) \mathrm{i}]$ inhibited surface at $20 \mu \mathrm{m},[(\mathrm{c}) \mathrm{c}$ ] corroded surface at $200 \mu \mathrm{m},[(\mathrm{c}) \mathrm{i}]$ inhibited surface at 200 $\mu \mathrm{m}$. 
damaged severely, as can be seen in Fig. 8(a)c-(c)c at different magnification levels of 5, 20 and $200 \mu \mathrm{m}$, respectively. It can be seen that pits are obvious and entirely covered with thick corrosion products. The corroded layer of the specimen is rather uneven and rusty with certain grooves. The aggressive ions can penetrate deep into the fresh aluminum alloy surface through these passages to form mordant corrosion products. After immersion in the UA Schiff base inhibitor test solution for $6 \mathrm{~h}$, an even and uniformly coated surface of the aluminum alloy substrate was observed as shown in Fig. 8(a)i-(c)i. There were no traces of corrosive compound formation on the surfaces, suggesting an efficient anticorrosive ability of the Schiff base. Furthermore, in comparison, a good protective film is evident, attributed to the effective adsorption of Schiff base, which protects from destructive ion attack on the surface of the metal substrate. The same anticorrosive response was observed for UB and UC test solutions.

3.4.3 Mechanism of corrosion inhibition. One can infer the mechanism of corrosion inhibition from the observations drawn from the various procedures and experimentation outlined above. Initially the Schiff base anticorrosive materials are adsorbed on the surface of aluminum alloy to form a protective film that guards the substrate even in an acidic medium of $0.1 \mathrm{M} \mathrm{HCl}$. The inhibitive action can be explained on the basis of nitrogen and oxygen atoms along with $\pi$ electron interaction of the aromatic rings with unshared $\mathrm{p}$ electrons of the aluminum atoms. In azomethine, $\mathrm{C}=\mathrm{N}$, the unshared pair of electrons of the nitrogen is easily available for sharing with metal atoms forming a covalent bond, hence the metal is protected from the acidic environment.

In the anticorrosion process, the adsorption of an anticorrosive material on a metallic substrate can be explained via three prime steps based on three different types of interactions whereby the process of adsorption may occur through one or more steps. ${ }^{\mathbf{6 0 , 6 1}}$ These three types of interactions are: electrostatic attraction between the charged molecules and charged metal, coordination of metal atoms with the unshared pair of electrons of molecules, and $\pi$ electron participation of the anticorrosive molecule in the process of coordination. Generally, the examined Schiff bases may be adsorbed on the aluminum alloy substrate in their protonated or neutral form, in the aqueous acidic solution. The interaction of neutral as well as protonated form on the substrate surface should be competitive with that of hydrogen ions, that are going to reduce the metal surface and hydrogen evolution occurs. As the aluminum alloy surface is positively charged in $0.1 \mathrm{M} \mathrm{HCl}$ solution, ${ }^{62,63} \mathrm{Cl}^{-}$ions (of $\mathrm{HCl}$ ) and investigated Schiff bases can be adsorbed on the aluminum surface via their negative centers. Adsorption on the aluminum alloy surface involves the displacement of aqueous molecules and sharing of electrons between the heteroatoms and aluminum alloy. Also, the anticorrosive molecules can adsorb on the surface of the aluminum alloy on the basis of donor-acceptor interactions between $\pi$ electrons of benzene rings and vacant p-orbitals of atoms of the aluminum alloy surface. ${ }^{3}$ Thus, it is concluded that charge sharing between the Schiff base molecules and metal is a more dominant type of adsorption than electrostatic interactions, and these are the main reasons of aluminum alloy corrosion inhibition. ${ }^{8}$ Among all the investigated Schiff bases, the chelating effect of UB and UC is greater as compared to UA. This is due to the presence of two electron-donating groups of $-\mathrm{OCH}_{3}$ in UB and two electron-donating groups of $-\mathrm{OC}_{2} \mathrm{H}_{5}$ in $\mathbf{U C}{ }^{3}$

\section{Conclusions}

Three novel Schiff bases were synthesized and their structures were interpreted spectroscopically through FT-IR, ${ }^{1} \mathrm{H}$ NMR, ${ }^{13} \mathrm{C}$ NMR and GC-MS. Corrosion inhibition efficiency of these synthesized Schiff bases on aluminum alloy AA2219-T6 in 0.1 M $\mathrm{HCl}$ was investigated using weight loss measurements, polarization and EIS studies. Molecular structure and corrosion inhibition efficiency of the title compounds were correlated with the help of quantum chemical calculations. The outcome of all tests showed that inhibition effectiveness of all the Schiff base inhibitors increases with increasing concentrations of inhibitors. All the inhibitor adsorptions followed the Langmuir adsorption isotherm showing predominant chemisorption, based on obtained $\Delta G_{\text {ads }}^{\circ}$ values, which showed that all the compounds are efficient corrosion inhibitors. Polarization studies showed all the Schiff bases as mixed-type inhibitors, having dominant cathodic action. Inhibition efficiency acquired from the weight loss and EIS are in good agreement with polarization studies in accordance with the order: $\mathbf{U C}>\mathbf{U B}$ $>$ UA for AA2219-T6 alloy. This inhibitor performance trend was set owing to the additional number of electron-donating functional groups $\mathrm{OCH}_{3}$ and $\mathrm{OC}_{2} \mathrm{H}_{5}$ attached to $\mathbf{U B}$ and $\mathrm{UC}$, resulting in higher inhibition efficiency. $E_{\mathrm{HOMO}}, E_{\mathrm{LUMO}}, \Delta E$, the dipole moment $(\mu)$, electronegativity, softness, hardness, charge transfer parameter, Mulliken charge along with charge transfer parameter were calculated through quantum chemical calculations. The values of $K_{\text {ads }}$ suggested strong interactions of inhibitors with the aluminum surface. Effective metal surface protection was further revealed through inspection of SEM images of surfaces in the presence of the investigated Schiff bases. The enhanced corrosion inhibition activity of these Schiff bases further aroused interest of our group to extend their application towards the development of anticorrosive paint for the paint industry, which is also a critical challenge for researchers in the field of corrosion science.

\section{Conflicts of interest}

There are no conflicts to declare.

\section{Acknowledgements}

U. N. is greatly obliged to the Higher Education Commission (HEC) of Pakistan (Pin No. 112-25825-2Ps1-592) for providing scholarship under the Program 5000 Indigenous PhD Scholarships and to the Department of Chemistry, Quaid-i-Azam University, Islamabad, Pakistan for providing research facilities. N. Z. A. gratefully acknowledges the funding received from the Directorate of Research \& Academic Coordination (RAC) National Centre for Physics Islamabad, Pakistan. F. U. S. is 
grateful for the financial support of the Norrbotten Research Council (NoFo 19-100).

\section{References}

1 R. Rosliza, W. B. W. Nik and H. B. Senin, The Effect of Inhibitor on the Corrosion of Aluminum Alloys in Acidic Solutions, Mater. Chem. Phys., 2008, 107, 281-288, DOI: 10.1016/ j.matchemphys.2007.07.013.

2 K. S. Rao and K. P. Rao, Corrosion Resistance of AA2219 Aluminium Alloy: Electrochemical Polarisation and Impedance Study, Mater. Sci. Technol., 2006, 22(1), 97-104, DOI: 10.1179/ $174328406 x 79405$.

3 S. P. Fakrudeen, C. A. Murthyh, V. B. Raju, H. C. Ananda Murthy and V. Bheema Raju, Corrosion Inhibition of AA6061 and AA6063 Alloy in Hydrochloric Acid Media by Schiff Base Compounds, J. Chil. Chem. Soc., 2012, 57(4), 1364-1371, DOI: 10.4067/S0717-97072012000400007.

4 A. Aytaç, $\mathrm{Cu}(\mathrm{II}), \mathrm{Co}(\mathrm{II})$ and $\mathrm{Ni}(\mathrm{II})$ Complexes of $-\mathrm{Br}$ and -OCH2CH3 Substituted Schiff Bases as Corrosion Inhibitors for Aluminium in Acidic Media, J. Mater. Sci., 2010, 45(24), 6812-6818, DOI: 10.1007/s10853-010-4779-7.

5 I. B. Obot, N. O. Obi-Egbedi, S. A. Umoren and E. E. Ebenso, Adsorption and Kinetic Studies on the Inhibition Potential of Fluconazole for the Corrosion of $\mathrm{Al}$ in $\mathrm{HCl}$ Solution, Chem. Eng. Commun., 2011, 198, 711-725, DOI: 10.1080/ 00986445.2011.532746.

6 R. Padash, M. R. Nasrabadi, A. Shokuhi, R. Ali, S. Nasab and T. Jesionowski, A Theoretical Study of Two Novel Schiff Bases as Inhibitors of Carbon Steel Corrosion in Acidic Medium, Appl. Phys. A, 2019, 125(2), 78, DOI: 10.1007/s00339-0182376-9.

7 H. Ashassi-Sorkhabi, D. Seifzadeh and M. G. E. N. Hosseini, EIS and Polarization Studies to Evaluate the Inhibition Effect of 3H-Phenothiazin-3-One, 7-Dimethylamin on Mild Steel Corrosion in $1 \mathrm{M} \mathrm{HCl}$ Solution, Corros. Sci., 2008, 50(12), 3363-3370, DOI: 10.1016/j.corsci.2008.09.022.

8 B. Duran and A. Yurt, Schiff Bases as Corrosion Inhibitor for Aluminium in HCl Solution, Corros. Sci., 2012, 54, 251-259, DOI: 10.1016/j.corsci.2011.09.026.

9 T. Zhang, W. Jiang, H. Wang and S. Zhang, Synthesis and Localized Inhibition Behaviour of New Triazine-Methionine Corrosion Inhibitor in $1 \mathrm{M} \mathrm{HCl}$ for 2024-T3 Aluminium Alloy, Mater. Chem. Phys., 2019, 237, 121866, DOI: 10.1016/ j.matchemphys.2019.121866.

10 A. K. Maayta, Inhibition of Acidic Corrosion of Pure Aluminum by Some Organic Compounds, Corros. Sci., 2004, 46, 1129-1140, DOI: 10.1016/j.corsci.2003.09.009.

11 E. E. Oguzie, Corrosion Inhibition of Aluminium in Acidic and Alkaline Media by Sansevieria Trifasciata Extract, Corros. Sci., 2007, 49, 1527-1539, DOI: 10.1016/ j.corsci.2006.08.009.

12 Q. Deng, H. Shi, N. Ding, B. Chen, X. He, G. Liu, Y. Tang, Y. Long and G. Chen, Novel Triazolyl Bis-Amino Acid Derivatives Readily Synthesized via Click Chemistry as Potential Corrosion Inhibitors for Mild Steel in HCl, Corros. Sci., 2012, 57, 220-227, DOI: 10.1016/j.corsci.2011.12.014.
13 Y. Yan, W. Li, L. Cai and B. Hou, Electrochimica Acta Electrochemical and Quantum Chemical Study of Purines as Corrosion Inhibitors for Mild Steel in $1 \mathrm{M} \mathrm{HCl}$ Solution, Electrochim. Acta, 2008, 53, 5953-5960, DOI: 10.1016/ j.electacta.2008.03.065.

14 M. Is, A. Asan and M. Kabasakalog, Corrosion Inhibition of Brass in Presence of Terdentate Ligands in Chloride Solution, Corros. Sci., 2005, 47, 1534-1544, DOI: 10.1016/ j.corsci.2004.07.031.

15 S. Varvara, L. Maria, K. Rahmouni and H. Takenouti, Evaluation of Some Non-Toxic Thiadiazole Derivatives as Bronze Corrosion Inhibitors in Aqueous Solution, Corros. Sci., 2008, 50, 2596-2604, DOI: 10.1016/j.corsci.2008.06.046.

16 K. F. Khaled, The Inhibition of Benzimidazole Derivatives on Corrosion of Iron in $1 \mathrm{M} \mathrm{HCl}$ Solutions, Electrochim. Acta, 2003, 48, 2493-2503, DOI: 10.1016/s0013-4686(03)00291-3.

17 J. O. Mendes, E. C. Silva and A. B. Rocha, On the Nature of Inhibition Performance of Imidazole on Iron Surface, Corros. Sci., 2012, 57, 254-259, DOI: 10.1016/j.corsci.2011.12.011.

18 A. Popova, M. Christov, S. Raicheva and E. Sokolova, Adsorption and Inhibitive Properties of Benzimidazole Derivatives in Acid Mild Steel Corrosion, Corros. Sci., 2004, 46, 1333-1350, DOI: 10.1016/j.corsci.2003.09.025.

19 P. Deepa and R. Padmalatha, Corrosion Behaviour of 6063 Aluminium Alloy in Acidic and in Alkaline Media, Arabian J. Chem., 2017, 10, S2234-S2244, DOI: 10.1016/ j.arabjc.2013.07.059.

20 S. P. Fakrudeen, Electrochemical Investigation of Corrosion Inhibition of AA6063 Alloy in 1M Hydrochloric Acid Using Schiff Base Compounds, IOSR J. Appl. Chem., 2012, 2(5), 37-47, DOI: 10.9790/5736-0253747.

21 S. Bonetti, R. Spengler, A. Petersen, L. S. Aleixo, A. A. Merlo and S. M. Tamborim, Surface-Decorated Silica with Schiff Base as an Anticorrosive Coating for Aluminium Alloy 2024-T3, Appl. Surf. Sci., 2019, 475, 684-694, DOI: 10.1016/ j.apsusc.2018.12.298.

22 U. J. Naik, P. C. Jha, M. Y. Lone, R. R. Shah and N. K. Shah, Electrochemical and Theoretical Investigation of the Inhibitory Effect of Two Schiff Bases of Benzaldehyde for the Corrosion of Aluminium in Hydrochloric Acid, J. Mol. Struct., 2016, 1125, 63-72, DOI: 10.1016/j.molstruc.2016.06.054.

23 R. S. Abdel Hameed, Schiff' Bases as Corrosion Inhibitor for Aluminum Alloy in Hydrochloric Acid Medium, Tenside, Surfactants, Deterg., 2019, 56(3), 209-215, DOI: 10.3139/ 113.110622.

24 F. B. Ravari, A. Dadgarinezhad and I. Shekhshoaei, Investigation on Two Salen Type Schiff Base Compounds as Corrosion Inhibition of Copper in $0.5 \mathrm{M} \mathrm{H}_{2} \mathrm{SO}_{4}$, Gazi Univ. J. Sci., 2009, 22(3), 175-182.

25 M. A. Bedair, S. A. Soliman, M. A. Hegazy, I. B. Obot, A. S. Ahmed, S. A. Soliman, M. A. Hegazy, I. B. Obot and A. S. Ahmed, Empirical and Theoretical Investigations on the Corrosion Inhibition Characteristics of Mild Steel by Three New Schiff Base Derivatives, J. Adhes. Sci. Technol., 2019, 33, 1139-1168, DOI: 10.1080/01694243.2019.1582889.

26 I. Benmahammed, T. Douadi, S. Issaadi, M. Al-noaimi and S. Chafaa, Heterocyclic Schiff Bases as Corrosion 
Inhibitors for Carbon Steel in $1 \mathrm{M} \mathrm{HCl}$ Solution: Hydrodynamic and Synergetic Effect Solution: Hydrodynamic and Synergetic Effect, J. Dispersion Sci. Technol., 2019, 1-20, DOI: 10.1080/01932691.2019.1614038.

27 S. Chen, Y. Ren, B. Luo, Y. Guo and Y. Peng, A Quantum Chemical Study on Some Schiff Bases as Inhibitors of Mild Steel Corrosion in $\mathrm{HCl}$ Solution, Int. J. Electrochem. Sci., 2019, 14, 3824-3832, DOI: 10.20964/2019.04.34.

28 L. Marı, A. Martı, L. Martinez and D. Glossman-mitnik, Computational Simulations of the Molecular Structure and Corrosion Properties of Amidoethyl, Aminoethyl and Hydroxyethyl Imidazolines Inhibitors, Corros. Sci., 2006, 48, 4053-4064, DOI: 10.1016/j.corsci.2006.05.036.

29 F. Bentiss, F. Gassama, D. Barbry and L. Gengembre, Enhanced Corrosion Resistance of Mild Steel in Molar Hydrochloric Acid Solution by Theoretical and XPS Studies, Appl. Surf. Sci., 2006, 252, 2684-2691, DOI: 10.1016/ j.apsusc.2005.03.231.

30 N. Khalil, Quantum Chemical Approach of Corrosion Inhibition, Electrochim. Acta, 2003, 48, 2635-2640, DOI: 10.1016/s0013-4686(03)00307-4.

31 M. Murmu, S. K. Saha, N. C. Murmu and P. Banerjee, Effect of Stereochemical Conformation into the Corrosion Inhibitive Behaviour of Double Azomethine Based Schiff Bases on Mild Steel Surface in $1 \mathrm{Mol} \mathrm{L}-1 \mathrm{HCl}$ Medium: An Experimental, Density Functional Theory and Molecular Dynamics Simulation Study, Corros. Sci., 2019, 146, 134151, DOI: 10.1016/j.corsci.2018.10.002.

32 I. B. Obot and N. O. Obi-egbedi, Colloids and Surfaces A: Physicochemical and Engineering Aspects Fluconazole as an Inhibitor for Aluminium Corrosion in $0.1 \mathrm{M} \mathrm{HCl}$, Colloids Surf., A, 2008, 330, 207-212, DOI: 10.1016/ j.colsurfa.2008.07.058.

33 S. K. Saha, A. Dutta, P. Ghosh, D. Sukul and P. Banerjee, Adsorption and Corrosion Inhibition Effect of Schiff Base Molecules on the Mild Steel Surface in $1 \mathrm{M} \mathrm{HCl} \mathrm{Medium:} \mathrm{A}$ Combined Experimental and Theoretical Approach, Phys. Chem. Chem. Phys., 2015, 17, 5679-5690, DOI: 10.1039/ c4cp05614k.

34 M. Talari, S. M. Nezhad, S. J. Alavi, M. Mohtashamipour, A. Davoodi and S. Hosseinpour, Experimental and Computational Chemistry Studies of Two Imidazole-Based Compounds as Corrosion Inhibitors for Mild Steel in $\mathrm{HCl}$ Solution, J. Mol. Liq., 2019, 110915, DOI: 10.1016/ j.molliq.2019.110915.

35 G. Greber, Vogel's Textbook of Practical Organic Chemistry (5th Ed.), Revised by Brian S. Furniss, Antony J. Hannaford, Peter W. G. Smith, and Austin R. Tatchell, John Wiley \& Sons, New York, 1514 Pp, J. Polym. Sci., Part A: Polym. Chem., 1991, 29(8), 1223, DOI: 10.1002/ pola.1991.080290821.

36 S. R. Gupta, P. Mourya, M. M. Singh and V. P. Singh, Synthesis, Structural, Electrochemical and Corrosion Inhibition Properties of Two New Ferrocene Schiff Bases Derived from Hydrazides, J. Organomet. Chem., 2014, 767, 136-143, DOI: 10.1016/j.jorganchem.2014.05.038.
37 K. F. Khaled, Electrochemical Investigation and Modeling of Corrosion Inhibition of Aluminum in Molar Nitric Acid Using Some Sulphur-Containing Amines, Corros. Sci., 2010, 52(9), 2905-2916, DOI: 10.1016/j.corsci.2010.05.001.

38 I. Lukovits, E. Kálmán and F. Zucchi, Corrosion Inhibitors Correlation Between Electronic Structure and Efficiency, Corrosion, 2001, 57(1), 3-8.

39 I. B. Obot and Z. M. Gasem, Theoretical Evaluation of Corrosion Inhibition Performance of Some Pyrazine Derivatives, Corros. Sci., 2014, 83, 359-366, DOI: 10.1016/ j.corsci.2014.03.008.

40 H. Hamani, T. Douadi, M. Al-noaimi, S. Issaadi, D. Daoud and S. Chafaa, Electrochemical and Quantum Chemical Studies of Some Azomethine Compounds as Corrosion Inhibitors for Mild Steel in 1M Hydrochloric Acid, Corros. Sci., 2014, 88, 234-245, DOI: 10.1016/j.corsci.2014.07.044.

41 K. Boumhara, F. Bentiss, M. Tabyaoui, J. Costa, J. Desjobert and A. Bellaouchou, Use of Artemisia Mesatlantica Essential Oil as Green Corrosion Inhibitor for Mild Steel in $1 \mathrm{M}$ Hydrochloric Acid Solution, Int. J. Electrochem. Sci., 2014, 9, 1187-1206.

42 A. Singh, K. R. Ansari, J. Haque, P. Dohare, H. Lgaz, R. Salghi and M. A. Quraishi, Effect of Electron Donating Functional Groups on Corrosion Inhibition of Mild Steel in Hydrochloric Acid: Experimental and Quantum Chemical Study, J. Taiwan Inst. Chem. Eng., 2018, 82, 233-251, DOI: 10.1016/j.jtice.2017.09.021.

43 M. Ramadan, E. Sayed, H. Shokry, T. Sharshar and M. A. Amin, A Newly Synthesized Sulphated 8-Hydroxyquinoline Derivative to Effectively Control Aluminum Corrosion in Perchloric Acid: Electrochemical and Positron Annihilation Studies, J. Mol. Liq., 2016, 214, 319-334, DOI: 10.1016/j.molliq.2015.11.056.

44 Q. Zhao, T. Tang, P. Dang, Z. Zhang and F. Wang, The Corrosion Inhibition Effect of Triazinedithiol Inhibitors for Aluminum Alloy in a $1 \mathrm{M} \mathrm{HCl}$ Solution, Metals, 2017, 7, 44, DOI: $10.3390 /$ met7020044.

45 N. Nnaji, N. Nwaji and J. Mack, Corrosion Resistance of Aluminum against Acid Activation: Impact of BenzothiazoleSubstituted Gallium Phthalocyanine, Molecules, 2019, 24, 207, DOI: $10.3390 /$ molecules24010207.

46 J. Saranya, M. Sowmiya, P. Sounthari, K. Parameswari, S. Chitra and K. Senthilkumar, N-Heterocycles as Corrosion Inhibitors for Mild Steel in Acid Medium, J. Mol. Liq., 2016, 216, 42-52, DOI: 10.1016/j.molliq.2015.12.096.

47 Z. Tao, S. Zhang, W. Li and B. Hou, Corrosion Inhibition of Mild Steel in Acidic Solution by Some Oxo-Triazole Derivatives, Corros. Sci., 2009, 51(11), 2588-2595, DOI: 10.1016/j.corsci.2009.06.042.

48 A. Khadraoui, A. Khelifa, L. Touafri, H. Hamitouche and R. Mehdaoui, Acid Extract of Mentha Pulegium as a Potential Inhibitor for Corrosion of 2024 Aluminum Alloy in $1 \mathrm{M}$ HCl Solution, J. Mater. Environ. Sci., 2013, 4(5), 663670.

49 S. S. Abd El Rehim, H. H. Hassan and M. A. Amin, Corrosion Inhibition of Aluminum by 1,1(Lauryl Amido)Propyl Ammonium Chloride in HCl Solution, Mater. Chem. Phys., 2001, 70(1), 64-72, DOI: 10.1016/s0254-0584(00)00468-5. 
50 S. K. Singh, S. P. Tambe, G. Gunasekaran, V. S. Raja and D. Kumar, Electrochemical Impedance Study of Thermally Sprayable Polyethylene Coatings, Corros. Sci., 2009, 51(3), 595-601, DOI: 10.1016/j.corsci.2008.11.025.

$51 \mathrm{X}$. Li and S. Deng, Inhibition Effect of Dendrocalamus Brandisii Leaves Extract on Aluminum in $\mathrm{HCl}, \mathrm{H} 3 \mathrm{PO} 4$ Solutions, Corros. Sci., 2012, 65, 299-308, DOI: 10.1016/ j.corsci.2012.08.033.

52 J. R. Macdonald, Impedance Spectroscopy, Ann. Biomed. Eng., 1992, 20(3), 289-305, DOI: 10.1007/bf02368532.

53 M. Behpour, S. M. Ghoreishi, N. Soltani and M. SalavatiNiasari, The Inhibitive Effect of Some Bis-N,S-Bidentate Schiff Bases on Corrosion Behaviour of 304 Stainless Steel in Hydrochloric Acid Solution, Corros. Sci., 2009, 51(5), 1073-1082, DOI: 10.1016/j.corsci.2009.02.011.

54 S. Banerjee, A. Mishra, M. M. Singh, B. Maiti, B. Ray and P. Maiti, Highly Efficient Polyurethane Ionomer Corrosion Inhibitor: The Effect of Chain Structure, RSC Adv., 2011, 1(2), 199-210, DOI: 10.1039/c1ra00021g.

55 K. F. Khaled, Monte Carlo Simulations of Corrosion Inhibition of Mild Steel in 0.5 M Sulphuric Acid by Some Green Corrosion Inhibitors, J. Solid State Electrochem., 2009, 13, 1743-1756, DOI: 10.1007/s10008-009-0845-y.

56 L. Guo, S. Zhu, S. Zhang, Q. He and W. Li, Theoretical Studies of Three Triazole Derivatives as Corrosion Inhibitors for Mild Steel in Acidic Medium, Corros. Sci., 2014, 87, 366-375, DOI: 10.1016/j.corsci.2014.06.040.

57 A. Kosari, M. H. Moayed, A. Davoodi, R. Parvizi, M. Momeni, H. Eshghi and H. Moradi, Electrochemical and Quantum
Chemical Assessment of Two Organic Compounds from Pyridine Derivatives as Corrosion Inhibitors for Mild Steel in HCl Solution under Stagnant Condition and Hydrodynamic Flow, Corros. Sci., 2014, 78, 138-150.

58 I. Ahamad, R. Prasad and M. A. Quraishi, Experimental and Quantum Chemical Characterization of the Adsorption of Some Schiff Base Compounds of Phthaloyl Thiocar -bohydrazide on the Mild Steel in Acid Solutions, Mater. Chem. Phys., 2010, 124(2-3), 1155-1165, DOI: 10.1016/ j.matchemphys.2010.08.051.

59 R. G. Pearson, Absolute Electronegativity and Hardness: Application to Inorganic Chemistry, Inorg. Chem., 1997, 8441(7), 3533-3539.

60 V. R. Saliyan and A. V. Adhikari, Propanohydrazide as an Effective Inhibitor of Mild Steel Corrosion in $\mathrm{HCl}$ Solution, Synthesis, 2008, 50, 55-61, DOI: 10.1016/j.corsci.2006.06.035.

61 D. Paul Schweinsberg, G. A. George, A. K. Nanayakkara and D. A. Steinert, The Protective Action of Epoxy Resins and Curing Agents-Inhibitive Effects on the Aqueous Acid Corrosion of Iron and Steel, Corros. Sci., 1988, 28(1), 33-42, DOI: 10.1016/0010-938x(88)90004-2.

62 A. Yurt, S. Ulutas and H. Dal, Electrochemical and Theoretical Investigation on the Corrosion of Aluminium in Acidic Solution Containing Some Schiff Bases, Appl. Surf. Sci., 2006, 253(2), 919-925, DOI: 10.1016/j.apsusc.2006.01.026.

63 A. K. Vijh, Chemical Approaches to the Approximate Prediction of Band Gaps of Binary Semiconductors and Insulators, J. Electrochem. Soc., 2007, 117(5), 173C, DOI: 10.1149/1.2407577. 